\title{
The First Self-Assembled Trimetallic Lanthanide Helicates Driven by Positive Cooperativity
}

\author{
Sébastien Floquet, ${ }^{[a]}$ Nadjet Ouali, ${ }^{[a]}$ Bernard Bocquet, ${ }^{[a]}$ Gérald Bernardinelli, ${ }^{[b]}$ \\ Daniel Imbert, ${ }^{[\mathrm{cc}}{ }^{\text {Jean-Claude G. Bünzli, }}{ }^{[\mathrm{c}]}$ Gérard Hopfgartner, $^{[\mathrm{d}]}$ and Claude Piguet*[a]
}

\begin{abstract}
The segmental tris-tridentate ligand $\mathrm{L} 7$ reacts with stoichiometric quantities of $\mathrm{Ln}^{\mathrm{III}}(\mathrm{Ln}=\mathrm{La}-\mathrm{Lu})$ in acetonitrile to give the complexes $\left[\operatorname{Ln}_{2}(\mathrm{~L} 7)_{3}\right]^{6+}$ and $\left[\operatorname{Ln}_{3}(\mathrm{~L} 7)_{3}\right]^{9+}$. Formation constants point to negligible sizediscriminating effects along the lanthanide series, but Scatchard plots suggest that the self-assembly of the trimetallic triple-stranded helicates $\left[\operatorname{Ln}_{3}(\mathrm{~L} 7)_{3}\right]^{9+}$ is driven to completion by positive cooperativity, despite strong intermetallic electrostatic repulsions. Crystallization provides quantitatively $\left[\mathrm{Ln}_{3}(\mathrm{~L} 7)_{3}\right]-$ $\left(\mathrm{CF}_{3} \mathrm{SO}_{3}\right)_{9}(\mathrm{Ln}=\mathrm{La}, \mathrm{Eu}, \mathrm{Gd}, \mathrm{Tb}, \mathrm{Lu})$ and the $\mathrm{X}$-ray crystal structure of $\left[\mathrm{Eu}_{3}(\mathrm{~L} 7)_{3}\right]\left(\mathrm{CF}_{3} \mathrm{SO}_{3}\right)_{9} \cdot\left(\mathrm{CH}_{3} \mathrm{CN}\right)_{9} \cdot\left(\mathrm{H}_{2} \mathrm{O}\right)_{2}$ $\left(\mathrm{Eu}_{3} \mathrm{C}_{216} \mathrm{H}_{226} \mathrm{~N}_{48} \mathrm{O}_{35} \mathrm{~F}_{27} \mathrm{~S}_{9}\right.$, triclinic, $P \overline{1}$, $Z=2$ ) shows the three ligand strands wrapped around a pseudo-threefold axis
\end{abstract}

defined by the three metal ions rigidly held at about $9 \AA$. Each metal ion is coordinated by nine donor atoms in a pseudo-trigonal prismatic arrangement, but the existence of terminal carboxamide units in the ligand strands differentiates the electronic properties of the terminal and the central metallic sites. Photophysical data confirm that the three coordination sites possess comparable pseudo-trigonal symmetries in the solid state and in solution. High-resolution luminescence analyses evidence a low-lying LMCT state affecting the

Keywords: cooperative effects
crystal-field parameters $\cdot$ helical
structures $\quad$ lanthanides
self-assembly

central $\mathrm{EuN}_{9}$ site, so that multi-metalcentered luminescence is essentially dominated by the emission from the two terminal $\mathrm{EuN}_{6} \mathrm{O}_{3}$ sites in $\left[\mathrm{Eu}_{3}(\mathrm{~L} 7)_{3}\right]^{9+}$. New multicenter equations have been developed for investigating the solution structure of $\left[\operatorname{Ln}_{3}(\mathrm{~L} 7)_{3}\right]^{9+}$ by paramagnetic NMR spectroscopy and linear correlations for $\mathrm{Ln}=\mathrm{Ce}-\mathrm{Tb}$ imply isostructurality for these larger lanthanides. NMR spectra point to the triple helical structure being maintained in solution, but an inversion of the magnitude of the second-rank crystal-field parameters, obtained by LIS analysis, for the $\mathrm{LnN}_{6} \mathrm{O}_{3}$ and $\mathrm{LnN}_{9}$ sites with respect to the parameters extracted for $\mathrm{Eu}^{\mathrm{III}}$ from luminescence data, suggests that the geometry of the central $\mathrm{LnN}_{9}$ site is somewhat relaxed in solution.

\section{Introduction}

Although interelectronic repulsions in open-shell configurations induce rich and varied optical and magnetic properties for d-block metal ions, the strong mixing between metal- and ligand-centered orbitals in their complexes drastically limits the programming of electronic properties in molecular or supramolecular devices. ${ }^{[1]}$ For the lanthanide ions $\left(\mathrm{Ln}^{\mathrm{III}}\right)$, the [a] Prof. Dr. C. Piguet, Dr. S. Floquet, Dr. N. Ouali, B. Bocquet Department of Inorganic, Analytical and Applied Chemistry University of Geneva, 30 quai E. Ansermet

1211 Geneva 4 (Switzerland)

Fax: $(+41) 22-702-6830$

E-mail: claude.piguet@chiam.unige.ch

[b] Dr. G. Bernardinelli

Laboratory of X-ray crystallography

University of Geneva, 24 quai E. Ansermet

1211 Geneva 4 (Switzerland)

[c] Dr. D. Imbert, Prof. Dr. J.-C. G. Bünzli

Institute of Molecular and Biological Chemistry

Swiss Federal Institute of Technology BCH 1402, 1015 Lausanne (Switzerland)

[d] Prof. Dr. G. Hopfgartner

School of Pharmacy

Laboratory of Analytical Pharmaceutical Chemistry

University of Geneva, 20 bd d'Yvoy

1211 Geneva 4 (Switzerland)
Supporting information for this article is available on the WWW under http://www.chemeurj.org or from the author. Table S1 lists the ESI-MS peaks observed during titrations and Table S2 lists elemental analyses for complexes 5-9. Tables S3 and S4 list selected least-square plane data for 10, and Tables S5-S7 give the structural data for the europium coordination spheres. Geometrical $G_{i}^{m}$ factors for the aromatic protons of $\mathbf{1 0}$ are given in Table S8, the integrated luminescence intensities of the $\mathrm{Eu}\left({ }^{7} \mathrm{~F}_{j}\right)$ energy levels of $\left[\mathrm{Eu}_{3}(\mathrm{~L} 7)_{3}\right]\left(\mathrm{CF}_{3} \mathrm{SO}_{3}\right)_{9} \cdot\left(\mathrm{H}_{2} \mathrm{O}\right)_{4}(6)$ are listed in Table S9, the energy of the ${ }^{5} \mathrm{D}_{0} \leftarrow{ }^{7} \mathrm{~F}_{0}$ transitions in Table S10, the $\mathrm{Eu}\left({ }^{5} \mathrm{D}_{0}\right)$ lifetimes in Table S11, while Table S12 lists the $\operatorname{Tb}\left({ }^{5} \mathrm{D}_{4}\right)$ lifetimes measured for $\left[\mathrm{Tb}_{3}(\mathrm{~L} 7)_{3}\right]\left(\mathrm{CF}_{3} \mathrm{SO}_{3}\right)_{9} \cdot\left(\mathrm{H}_{2} \mathrm{O}\right)_{12}$ (8). Figure S1 shows ESI-MS spectra obtained during the titration of $\mathrm{L} 7$ with $\mathrm{Eu}^{\mathrm{III}}$; Figure S2 shows the calculated ligand speciation during the titration L7 with $\mathrm{La}^{\mathrm{III}}$. Figure S3 displays a view of the unit cell in 10. Figures S4-S6 show emission spectra of $\left[\mathrm{Ln}_{3}(\mathrm{~L} 7)_{3}\right]^{9+}, \mathrm{Ln}=\mathrm{La}(\mathbf{5}), \mathrm{Eu}(\mathbf{6}), \mathrm{Gd}(\mathbf{7}), \mathrm{Tb}$ (8), and Lu (9). 
$4 \mathrm{f}$ orbitals are screened from external perturbations by outer filled $5 s^{2}$ and $5 p^{6}$ shells, ${ }^{[2]}$ and the electronic properties of their complexes can be rationally tuned by weak crystal-field effects resulting from the precise control of the coordination sphere $;{ }^{[3]}$ a crucial point for the implementation of specific functions. ${ }^{[4]}$ Sophisticated monometallic lanthanide complexes have been thus designed for operating as 1) efficient catalysts for asymmetric organic transformations, ${ }^{[5]}$ 2) contrast agents that possess two vacant coordination sites for magnetic resonance imaging (MRI) ${ }^{[6]} 3$ ) luminescent probes for sensing base-pairing in oligonucleotides, ${ }^{[7]}$ and 4) magnetically addressable metallomesogens. ${ }^{[8]}$ An increased density of magnetic or optical probes in polymetallic $\mathrm{f}-\mathrm{f}$ complexes offers new perspectives for programming molecular devices in that several lanthanide ions can be selectively introduced into the final architectures. ${ }^{[9-12]}$ For instance, the intermetallic energy transfers evidenced in the heterobimetallic helicates $\left[\operatorname{LnLn}^{\prime}\left(\mathrm{Li}_{3}\right]^{6+}(i=1,2)^{[13,14]}\right.$ and $\left[\operatorname{LnLn}^{\prime}(\mathrm{Li}-2 \mathrm{H})_{3}\right] \quad(i=3$, $4)^{[15,16]}$ have no counterpart in monometallic analogues, but the intrinsic equivalence of the metallic sites prevents the isolation of pure heterobimetallic complexes exhibiting directional magnetic ${ }^{[17]}$ and optical ${ }^{[18]}$ properties. The connection of two different tridentate binding units in the segmental ligand L5 partially solves this problem, and nonstatistical mixtures of homobimetallic $\left(\left[\mathrm{Ln}_{2}(\mathrm{~L} 5)_{3}\right]^{6+},\left[\operatorname{Ln}_{2}^{\prime}(\mathrm{L} 5)_{3}\right]^{6+}\right)$ and heterobimetallic triple-stranded helicates $\left(\left[\mathrm{LnLn}^{\prime}(\mathrm{L} 5)_{3}\right]^{6+}\right)$ are observed upon reaction with two different $\mathrm{Ln}^{\text {III }}$ ions. However, the formation of some head-to-head-to-tail (HHT) geometrical isomers as well as the major head-to-head-to-head ( $\mathrm{HHH})$ species limits the programming of specific functionalities in the final complexes. ${ }^{[19]}$ An alternative approach considers the $C_{2 v}$-symmetrical tris-tridentate segmental ligands L6, ${ }^{[20]} \mathrm{L} 7$, and L8, because the final trimetallic $D_{3}$-symmetrical helicates $\left[\mathrm{Ln}_{3}(\mathrm{Li})_{3}\right]^{9+}$ display no isomers, and the nonequivalence of the terminal NNO and the central NNN tridentate binding units provides different nine-coordinate metallic sites. In this paper, we demonstrate that 1 ) the strongly coordinating amide groups grafted at both ends of the tritopic receptor L7 overcomes electrostatic repulsions associated with the complexation of three lanthanide(III) in the triple-stranded helicates and 2) the thermodynamic assembly of $\left[\mathrm{Ln}_{3}(\mathrm{~L} 7)_{3}\right]^{9+}$ is driven to completion by positive cooperativity. Particular attention is focused on the consequences of the different crystal-field parameters generated by the nonequivalent metallic sites for controlling the magnetic and photophysical properties in the final complexes. A partial description of the crystal structure of $\left[\mathrm{Eu}_{3}(\mathrm{~L} 7)_{3}\right]^{9+}$ has been reported in a preliminary communication. ${ }^{[21]}$

\section{Results and Discussion}

Synthesis of ligands $\mathbf{L 7}$ and $\mathbf{L 8}$ : The $C_{2 v}$-symmetrical heterotopic ligand 2,6-bis\{1-ethyl-5-\{1-ethyl-2-[6-( $N, N$-diethylcarbamoyl)pyridin-2-yl]benzimidazol-5-methylene\}benzimidazole-2yl pyridine (L7) consists of two terminal carboxamide - pyridine-benzimidazole (ONN) segments connected through methylene spacers to a central tridentate bis(benzimidazole)pyridine unit. Ligand $\mathrm{L} 7 \cdot \mathrm{H}_{2} \mathrm{O}$ is obtained in three steps from the synthons $\mathbf{1}$ and $\mathbf{2}$ according to a strategy based on the preparation of four benzimidazole rings from the tetra[N-(2nitroarene)carboxamide] precursor 4 (Scheme 1). ${ }^{[22]}$ Harsh basic conditions are required to hydrolyse the terminal carboxamide units to give the poorly soluble dicarboxylic ligand L8 isolated as its salt $\mathrm{K}[\mathrm{L} 8-\mathrm{H}] \cdot 5.6 \mathrm{H}_{2} \mathrm{O}$. The lack of nuclear Overhauser effects (NOEs, ${ }^{1} \mathrm{H}$ NMR) between the ethyl group of the benzimidazole and the proton of the adjacent pyridine rings ( $\mathrm{H} 2$ or $\mathrm{H} 9)$ for $\mathrm{L} 7$ and L8 in solution points to transoid arrangements of the benzimidazole - pyridine units, as found for L2 and L3. ${ }^{[14,15]}$ Ligand L7 is soluble enough in acetonitrile to allow complexation studies, but the ambivalent lipophilic/hydrophilic nature of L8 prevents significant solubility in common solvents except hot DMSO, and no complexation study could be performed with this ligand.

Thermodynamic self-assembly processes of $\mathrm{L7}$ with $\mathrm{Ln}^{\mathrm{III}}$ : ESI-MS titrations of L7 $\left(2 \times 10^{-4} \mathrm{M}\right.$ in acetonitrile $)$ with $\mathrm{Ln}\left(\mathrm{CF}_{3} \mathrm{SO}_{3}\right)_{3} \cdot x \mathrm{H}_{2} \mathrm{O}(\mathrm{Ln}=\mathrm{La}, \mathrm{Eu}, \mathrm{Gd}, \mathrm{Tb}, \mathrm{Lu} ; x=1-4)$, for an Ln:L7 ratio in the range $0.1-1.2$, show the successive formation of two cationic complexes $\left[\operatorname{Ln}_{2}(\mathrm{~L} 7)_{3}\right]^{6+}$ and $\left[\mathrm{Ln}_{3}(\mathrm{~L} 7)_{3}\right]^{9+}$ together with their adduct ions $\left[\mathrm{Ln}_{2}(\mathrm{~L} 7)_{3^{-}}\right.$ $\left.\left(\mathrm{CF}_{3} \mathrm{SO}_{3}\right)_{n}\right]^{(6-n)+} \quad(n=1-3)$ and $\left[\mathrm{Ln}_{3}(\mathrm{~L} 7)_{3}\left(\mathrm{CF}_{3} \mathrm{SO}_{3}\right)_{n}\right]^{(9-n)+}$ $(n=1-7)$ (Table S1, Figure S1a and S1b in the Supporting Information). In the presence of excess metal ( $\mathrm{Ln}: \mathrm{L} 7>2.0)$, the peaks corresponding to $\left[\operatorname{Ln}_{3}(\mathrm{~L} 7)_{3}\right]^{9+}$ are replaced with new signals assigned to $\left[\mathrm{Ln}_{3}(\mathrm{~L} 7)_{2}\left(\mathrm{CH}_{3} \mathrm{CN}\right)_{x}\left(\mathrm{H}_{2} \mathrm{O}\right)_{y^{-}}\right.$
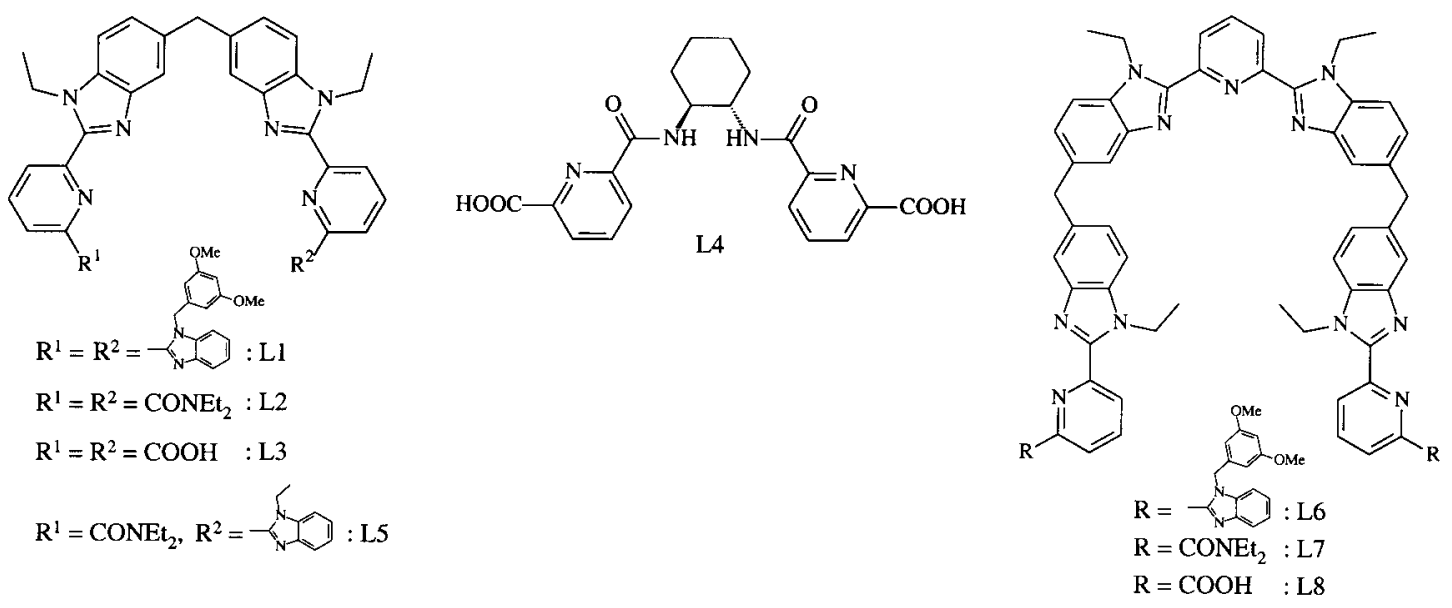
<smiles>CCNc1ccc(Cc2ccc(NCC)c([N+](=O)[O-])c2)cc1NCC</smiles><smiles>CCNc1ccc(Cc2ccc(N(CC)C(=O)c3cccc(C(=O)N(CC)CC)n3)c([N+](=O)[O-])c2)cc1[N+](=O)[O-]</smiles><smiles>C=CC(=C)c1nc2ccc(Cc3ccc4c(c3)nc(-c3cccc(C)n3)n4CC)cc2n1CC</smiles><smiles>CCN(CC)C(=O)c1cccc(C(=O)N(CC)c2ccc(Cc3ccc(N(CC)C(=O)c4cccc(Cc5ccc(N(CC)C(=O)c6cccc(N(CC)CC)c6[N+](=O)[O-])c([N+](=O)[O-])c5)n4)c([N+](=O)[O-])c3)cc2[N+](=O)[O-])n1</smiles>

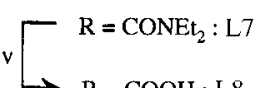

$\rightarrow \mathrm{R}=\mathrm{COOH}: \mathrm{L} 8$

Scheme 1. Reagents: i) $\mathrm{SOCl}_{2} / \mathrm{DMF}$; ii) $\mathrm{NEt}_{3}$; iii) 2,6-bis(chlorocarboxy)pyridine, $\mathrm{NEt}_{3}$; iv) $\mathrm{Fe}$, $\left.\mathrm{HCl}, \mathrm{EtOH} / \mathrm{H}_{2} \mathrm{O} ; \mathrm{v}\right) \mathrm{KOH}, \mathrm{EtOH} / \mathrm{H}_{2} \mathrm{O}$.

$\left.\left(\mathrm{CF}_{3} \mathrm{SO}_{3}\right)_{n}\right]^{(9-n)+}(n=3,5,7)$, which involve the formation of the "unsaturated" species $\left[\operatorname{Ln}_{3}(\mathrm{~L} 7)_{2}\right]^{9+}$ (Table S1 and Figure S1c in the Supporting Information).

Batch spectrophotometric titrations of L7 $\left(2 \times 10^{-4} \mathrm{M}\right)$ with $\mathrm{Ln}\left(\mathrm{CF}_{3} \mathrm{SO}_{3}\right)_{3} \cdot x \mathrm{H}_{2} \mathrm{O}(\mathrm{Ln}=\mathrm{La}, \mathrm{Nd}, \mathrm{Eu}, \mathrm{Tb}, \mathrm{Ho}, \mathrm{Tm}, \mathrm{Lu} ; x=$ $1-4)$ in acetonitrile display complicated variations of the absorption spectra with end points for $\operatorname{Ln}: \mathrm{L7}=1.0$ and 1.5 and a smooth inflexion around Ln:L7 $=0.5-0.7$ (Figure 1). Factor analysis ${ }^{[23]}$ points to the existence of four absorbing species $\left(\mathrm{L} 7,\left[\mathrm{Ln}_{2}(\mathrm{~L} 7)_{3}\right]^{6+},\left[\mathrm{Ln}_{3}(\mathrm{~L} 7)_{3}\right]^{9+}\right.$, and $\left[\mathrm{Ln}_{3}(\mathrm{~L} 7)_{2}\right]^{9+}$ ) in agreement with the ESI-MS results, and the spectrophotometric data can be fitted with nonlinear least-squares techniques ${ }^{[24]}$ to the equilibria given in Equations (1) - (3), which characterize the assembly process (the formation constants $\log \left(\beta_{i j}^{\mathrm{Ln}}\right)$ are collected in Table 1).

$$
\begin{array}{lr}
2 \mathrm{Ln}^{3+}+3 \mathrm{~L} 7 \rightleftarrows\left[\operatorname{Ln}_{2}(\mathrm{~L} 7)_{3}\right]^{6+} & \log \left(\beta_{23}^{\mathrm{Ln}}\right) \\
3 \mathrm{Ln}^{3+}+3 \mathrm{~L} 7 \rightleftarrows\left[\mathrm{Ln}_{3}(\mathrm{~L} 7)_{3}\right]^{9+} & \log \left(\beta_{33}^{\mathrm{Ln}}\right) \\
3 \mathrm{Ln}^{3+}+2 \mathrm{~L} 7 \rightleftarrows\left[\mathrm{Ln}_{3}(\mathrm{~L} 7)_{2}\right]^{9+} & \log \left(\beta_{32}^{\mathrm{Ln}}\right)
\end{array}
$$

The variables $\beta_{23}^{\mathrm{Ln}}$ and $\beta_{33}^{\mathrm{Ln}}$ do not vary significantly from their average values $\left(\log \left(\beta_{23}^{\mathrm{Ln}}\right)=25.7\right.$ and $\left.\log \left(\beta_{33}^{\mathrm{Ln}}\right)=34.6\right)$ within experimental error along the lanthanide series. The stability constants for the formation of the bimetallic complexes $\left[\mathrm{Ln}_{2}(\mathrm{~L} 7)_{3}\right]^{6+}$ is close to $\log \left(\beta_{23}^{\mathrm{Ln}}\right)=25.3-24.0$, obtained for $\left[\operatorname{Ln}_{2}(\mathrm{~L} 2)_{3}\right]^{6+}$ in the same conditions and for which the lanthanides are nine-coordinate by three wrapped NNO binding units. ${ }^{[14]}$ Complexation of three NNN binding units to $\mathrm{Ln}^{\mathrm{III}}$ in $\left[\mathrm{Ln}_{2}(\mathrm{~L} 1)_{3}\right]^{6+}$ produces less stable complexes $\left(\log \left(\beta_{23}^{\mathrm{Ln}}\right)=17.5-20.0\right){ }^{;[13]}$ this suggests that the two $\mathrm{Ln}^{\mathrm{III}}$ ions occupy the terminal nine-coordinate $\mathrm{N}_{6} \mathrm{O}_{3}$ sites in
$\left[\operatorname{Ln}_{2}(\mathrm{~L} 7)_{3}\right]^{6+}$, while the central $\mathrm{N}_{9}$ site remains unoccupied. The variable $\beta_{33}^{\mathrm{Ln}}$ reflects the stability of the trimetallic triple-stranded helicates $\left[\mathrm{Ln}_{3}(\mathrm{~L} 7)_{3}\right]^{9+}$ in which the three nine-coordinate sites (one central $\mathrm{N}_{9}$ and two terminal $\mathrm{N}_{6} \mathrm{O}_{3}$ sites) are occupied by metals. In contrast to the triple-helical complexes $\left[\operatorname{Ln}(\mathrm{L} 9)_{3}\right]^{3+}$, which display a marked<smiles>Cn1c(-c2cc(I)cc(-c3nc4ccccc4n3C)n2)nc2ccccc21</smiles>

preference for mid-range $\mathrm{Ln}^{\text {III, }}{ }^{[25]}$ the analogous central $\mathrm{LnN}_{9}$ metallic site in $\left[\mathrm{Ln}_{3}(\mathrm{~L} 7)_{3}\right]^{9+}$ does not exhibit significant size-discriminating effects; this is in agreement with the removal of intramolecular interstrand repulsions occur-
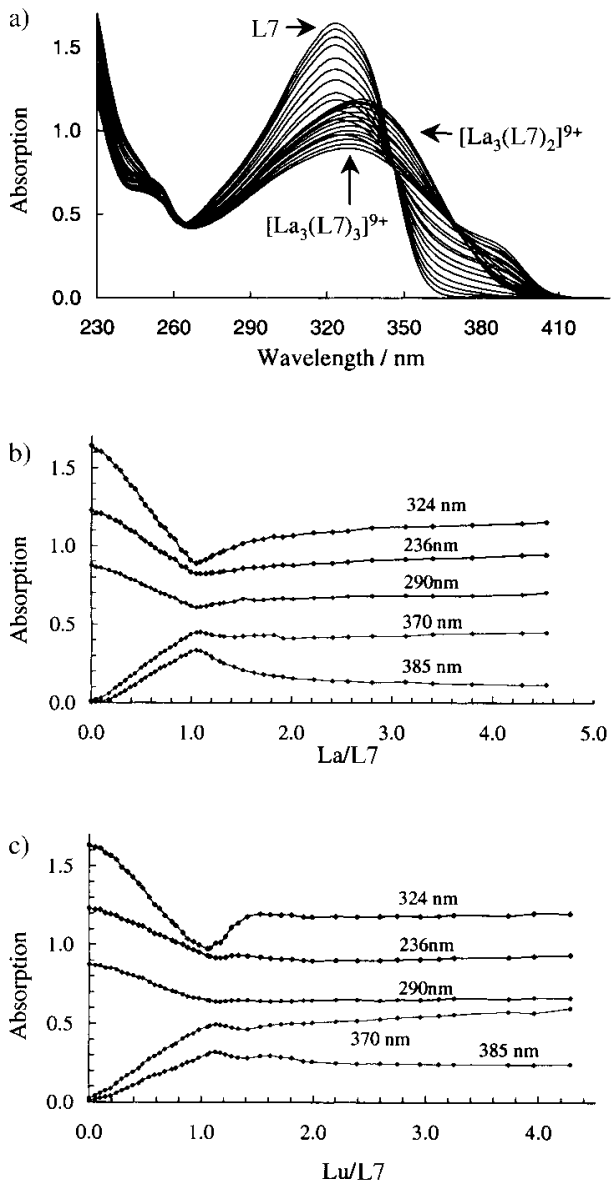

Figure 1. a) Variation of the absorption spectra observed during the spectrophotometric batch titration of $\mathrm{L} 7\left(2 \times 10^{-4} \mathrm{M}\right)$ with $\mathrm{La}\left(\mathrm{CF}_{3} \mathrm{SO}_{3}\right)_{3}$. $2 \mathrm{H}_{2} \mathrm{O}$ in acetonitrile at $298 \mathrm{~K}$ ( $\mathrm{Ln}: \mathrm{L} 7$ in the range $\left.0.1-4.3\right)$. b) Corresponding variation of the absorption at five different wavelengths for $\mathrm{Ln}=$ La. c) Variation of the absorption at five different wavelengths for $\mathrm{Ln}=\mathrm{Lu}$. 
Table 1. Formation constants $\log \left(\beta_{i j}^{\mathrm{Ln}}\right)$ for the complexes $\left[\operatorname{Ln}_{i}(\mathrm{~L} 7)_{j}\right]^{3 i+}$ in acetonitrile at $298 \mathrm{~K}$.

\begin{tabular}{llllr}
\hline $\mathrm{Ln}^{\mathrm{III}}$ & $\log \left(\beta_{23}\right)$ & $\log \left(\beta_{33}\right)$ & $\log \left(\beta_{32}\right)$ & $\log \left(K_{4}\right)^{[\mathrm{a}]}$ \\
\hline $\mathrm{La}^{\mathrm{III}}$ & $25.0 \pm 1.1$ & $34.3 \pm 1.2$ & $25.8 \pm 1.1$ & $8.8 \pm 1.5$ \\
$\mathrm{Nd}^{\mathrm{III}}$ & $26.0 \pm 1.0$ & $35.0 \pm 1.1$ & $26.4 \pm 1.0$ & $9.2 \pm 1.1$ \\
$\mathrm{Eu}^{\mathrm{III}}$ & $25.9 \pm 1.4$ & $34.8 \pm 1.6$ & $26.0 \pm 1.4$ & $8.4 \pm 1.5$ \\
$\mathrm{~Tb}^{\mathrm{III}}$ & $25.8 \pm 0.2$ & $35.0 \pm 1.2$ & $27.2 \pm 0.1$ & $11.6 \pm 0.9$ \\
$\mathrm{Ho}^{\mathrm{III}}$ & $26.0 \pm 1.0$ & $35.0 \pm 1.2$ & $26.5 \pm 1.0$ & $9.5 \pm 1.1$ \\
$\mathrm{Tm}^{\mathrm{III}}$ & $26.0 \pm 1.6$ & $34.5 \pm 1.8$ & $26.9 \pm 0.9$ & $11.7 \pm 1.4$ \\
$\mathrm{Lu}^{\text {III }}$ & $25.5 \pm 1.1$ & $33.9 \pm 0.3$ & $27.4 \pm 0.5$ & $14.4 \pm 0.4$ \\
\hline
\end{tabular}

[a] $\log \left(K_{4}^{\mathrm{Ln}}\right)=3 \log \left(\beta_{32}^{\mathrm{Ln}}\right)-2 \log \left(\beta_{33}^{\mathrm{Ln}}\right) \quad$ calculated by using the centroid values of the formation constants.

ring between the closely packed benzimidazole rings (vide infra, Figure 6). Finally, the slight increase of $\log \left(\beta_{32}^{\mathrm{Ln}}\right)$ in going from $\mathrm{Ln}=\mathrm{La}$ to $\mathrm{Lu}$ suggests a reduced stability of the triplehelix in the presence of excess metal for small $\mathrm{Ln}^{\mathrm{III}}$ ions, as exemplified by the trend of the estimated centroids of the equilibrium constants $\log \left(K_{4}^{\mathrm{Ln}}\right)=3 \log \left(\beta_{32}^{\mathrm{Ln}}\right)-2 \log \left(\beta_{33}^{\mathrm{Ln}}\right)$ [Eq. (4) and Table 1].

$$
2\left[\operatorname{Ln}_{3}(\mathrm{~L} 7)_{3}\right]^{9+}+3 \operatorname{Ln}^{3+} \rightleftarrows 3\left[\operatorname{Ln}_{3}(\mathrm{~L} 7)_{2}\right]^{9+} \quad \log \left(K_{4}^{\mathrm{Ln}}\right)
$$

The distribution curves computed by using the formation constants reported in Table 1 show that the trimetallic complexes $\left[\mathrm{Ln}_{3}(\mathrm{~L} 7)_{3}\right]^{9+}$ are almost quantitatively formed for $\mathrm{Ln}: \mathrm{L} 7$ close to 1.0 , but the decomposition into $\left[\mathrm{Ln}_{2}(\mathrm{~L} 7)_{3}\right]^{6+}$ in the presence of excess ligand, or into $\left[\mathrm{Ln}_{3}(\mathrm{~L} 7)_{2}\right]^{9+}$ in the presence of excess metal is favored for small $\mathrm{Ln}^{\mathrm{III}}$ (Figure 2). Finally, parallel spectrophotometric titrations of L7 with

a)

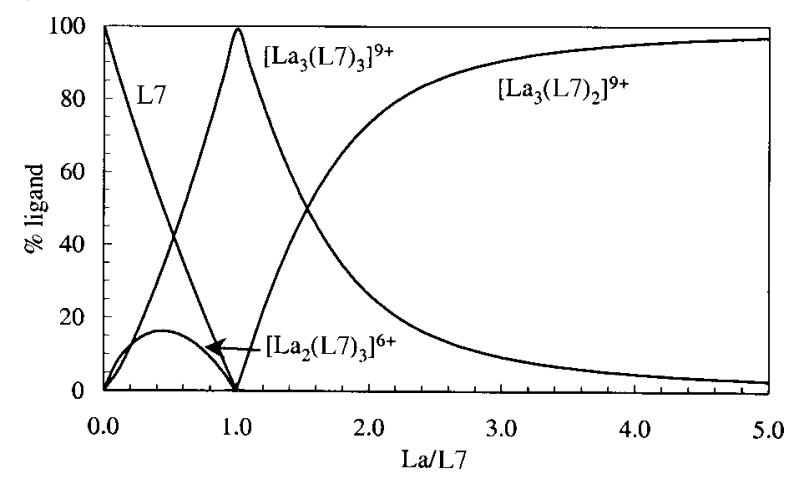

b)

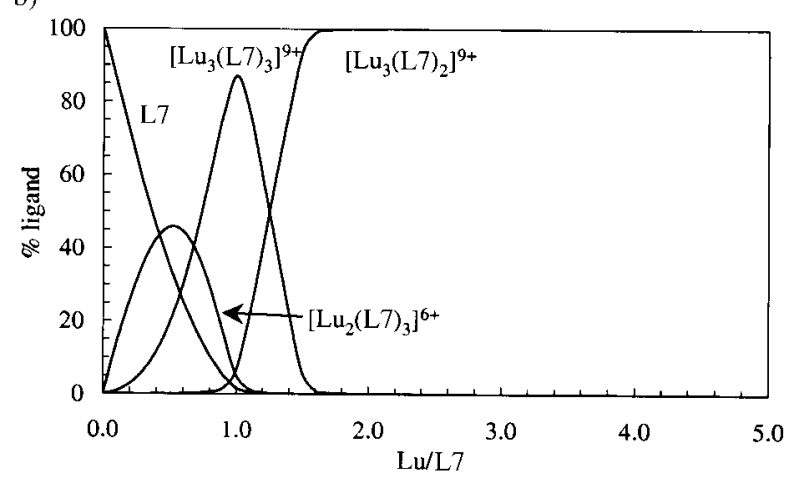

Figure 2. Calculated ligand speciation curves in acetonitrile for a total ligand concentration of $2 \times 10^{-4} \mathrm{M}$ and $\mathrm{Ln}: \mathrm{L} 7$ in the range $0.1-5.0:$ a) $\mathrm{Ln}=$ $\mathrm{La}^{\mathrm{III}}$, b) $\mathrm{Ln}=\mathrm{Lu}^{\mathrm{III}}$.
$\mathrm{Ln}\left(\mathrm{ClO}_{4}\right)_{3} \cdot x \mathrm{H}_{2} \mathrm{O}$ in acetonitrile give $\log \left(\beta_{i j}\right)$, which are identical within experimental errors to those reported in Table 1. This rules out some specific coordinating behavior of $\mathrm{CF}_{3} \mathrm{SO}_{3}{ }^{-}$that could be responsible for the formation of the "unsaturated" complexes $\left[\mathrm{Ln}_{3}(\mathrm{~L} 7)_{2}\right]^{9+}$ in the presence of excess metal.

The two formation constants $\beta_{23}$ and $\beta_{33}$ allow an estimate of the cooperativity of the assembly process leading to the trimetallic triple-stranded helicates $\left[\mathrm{Ln}_{3}(\mathrm{~L} 7)_{3}\right]^{9+} \cdot{ }^{[26-28]}$ According to the speciation reported on Figure 2, the formation of $\left[\mathrm{Ln}_{3}(\mathrm{~L} 7)_{2}\right]^{9+}$ can be neglected for $\mathrm{Ln}: \mathrm{L} 7$ ratios in the range $0.1-1.0$, and the occupancy factor $r$ corresponding to the average number of sites occupied by the metal in the triplehelix is thus given by Equation (5): ${ }^{[26]}$

$r=\frac{|\mathrm{Ln}|_{\text {bound }}}{\left|(\mathrm{L} 7)_{3}\right|}=3 \frac{|\operatorname{Ln}|_{\text {bound }}}{\left|\mathbf{L} 7_{\text {total }}\right|}=\frac{3\left(|\operatorname{Ln}|_{\text {total }}-|\mathrm{Ln}|\right)}{\left|\mathbf{L} 7_{\text {total }}\right|}=\frac{3 \sum_{m} m \beta_{\mathrm{m} 3}|\operatorname{Ln}|^{m}|\mathbf{L} 7|^{2}}{1+3 \sum_{m} \beta_{\mathrm{m} 3}|\operatorname{Ln}|^{\mathrm{m}}|\mathrm{L} 7|^{2}}$

Plots of $r /|\operatorname{Ln}|$ as a function of $r$ (Scatchard plots) ${ }^{[26 b]}$ correspond to reliable tests for cooperativity, because a straight line is expected when the successive binding of the metal ions is statistical (i.e., no cooperativity occurs), while concave downward or convex upward curves characterize positive or negative cooperativity, respectively. ${ }^{[26]}$ The Scatchard plots obtained for $\left[\mathrm{Ln}_{3}(\mathrm{~L} 7)_{3}\right]^{9+}(\mathrm{Ln}=\mathrm{La}, \mathrm{Eu}, \mathrm{Lu})$ are similar and concave; this implies that the self-assembly processes are driven to completion by positive cooperativity as previously reported for trimetallic $\mathrm{Ag}^{\mathrm{I}[27]}$ and $\mathrm{Cu}^{\mathrm{I}[28]}$ doublestranded helicates (Figure 3). Since $\beta_{13}$ is not accessible, the

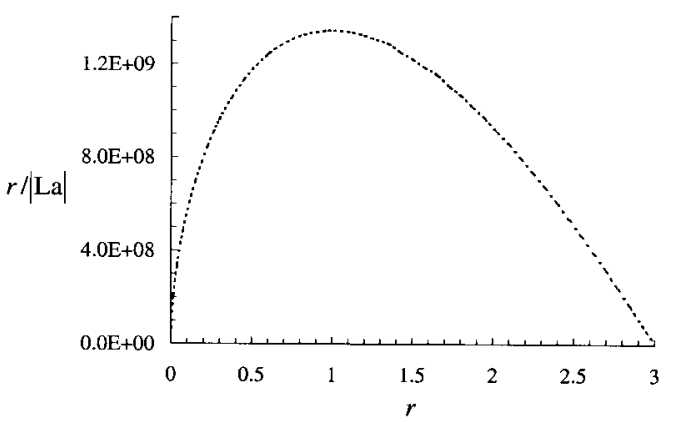

Figure 3. Scatchard plot for the formation of the triple-stranded helicate $\left[\mathrm{La}_{3}(\mathrm{~L} 7)_{3}\right]^{9+}$ in acetonitrile.

cooperativity process refers to the fixation of the third lanthanide ion with respect to the average binding of the metal ions in $\left[\mathrm{Ln}_{2}(\mathrm{~L} 7)_{3}\right]^{6+}$, and we conclude that electrostatic repulsion associated with the complexation of the third $\mathrm{Ln}^{\mathrm{III}}$ is more than compensated by the preorganization of the receptor brought about by the first two metal ions. Related Scatchard plots for the bimetallic helicates $\left[\operatorname{Ln}_{2}(\mathrm{~L} 1)_{3}\right]^{6+}(\mathrm{Ln}=$ $\mathrm{La}, \mathrm{Eu}, \mathrm{Lu})$ display convex curves and negative cooperativity $;^{[29]}$ this highlights the crucial role played by 1$)$ the ligand design (i.e., the replacement of terminal benzimidazole groups in L1 or L6 ${ }^{[20]}$ with carboxamide groups in L7) and 2) the overall nuclearity of the assembly processes.

${ }^{1} \mathrm{H}$ NMR titrations of $\mathrm{L} 7\left(5 \times 10^{-3} \mathrm{M}\right)$ with $\mathrm{Ln}\left(\mathrm{CF}_{3} \mathrm{SO}_{3}\right)_{3}$. $x \mathrm{H}_{2} \mathrm{O}(\mathrm{Ln}=\mathrm{La}, \mathrm{Eu}, \mathrm{Lu} ; \mathrm{x}=1-4)$ in $\mathrm{CD}_{3} \mathrm{CN}$ qualitatively confirm the successive formation of the three complexes 
$\left[\operatorname{Ln}_{2}(\mathrm{~L} 7)_{3}\right]^{6+},\left[\operatorname{Ln}_{3}(\mathrm{~L} 7)_{3}\right]^{9+}$, and $\left[\operatorname{Ln}_{3}(\mathrm{~L} 7)_{2}\right]^{9+}$. According to the speciation at this concentration, we expect $\left[\operatorname{Ln}_{3}(\mathrm{~L} 7)_{3}\right]^{9+}$ to be the major species for Ln:L7 in the range $0.8-1.3$, and it is quantitatively formed for $\mathrm{Ln}: \mathrm{L} 7=1.0$ (Figure S2 in the Supporting Information). The ${ }^{1} \mathrm{H}$ NMR spectra of $\left[\mathrm{Ln}_{3}(\mathrm{~L} 7)_{3}\right]^{9+}(\mathrm{Ln}=\mathrm{La}, \mathrm{Eu}, \mathrm{Lu})$ display 25 signals characteristic of the quantitative formation of a racemic mixture of the triple-stranded helicates $P P P-\left[\operatorname{Ln}_{3}(\mathrm{~L} 7)_{3}\right]^{9+}$ and $M M M$ $\left[\mathrm{Ln}_{3}(\mathrm{~L} 7)_{3}\right]^{9+}$ (Figure 4a, detailed assignments and discussion
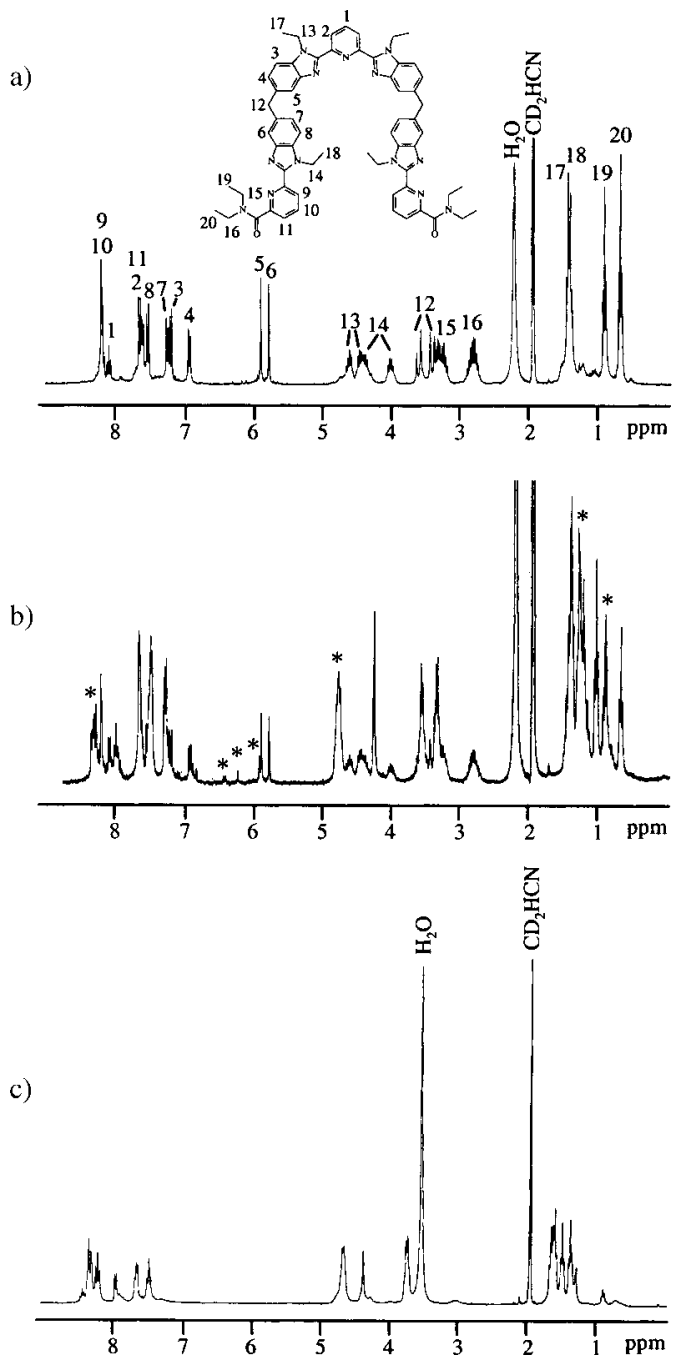

Figure 4. ${ }^{1} \mathrm{H}$ NMR spectra obtained during the titration of $\mathrm{L} 7$ with $\mathrm{La}\left(\mathrm{CF}_{3} \mathrm{SO}_{3}\right)_{3} \cdot 2 \mathrm{H}_{2} \mathrm{O}$ in $\mathrm{CD}_{3} \mathrm{CN}(298 \mathrm{~K})$ : a) $\mathrm{La}: \mathrm{L} 7=1.0$, b) $\mathrm{La}: \mathrm{L} 7=0.4$ (* indicates peaks specific to $\left[\mathrm{La}_{2}(\mathrm{~L} 7)_{3}\right]^{6+}$ ) and c) $\mathrm{La}: \mathrm{L} 7=3.0$.

are given in the section dedicated to the solution structure of $\left.\left[\mathrm{Ln}_{3}(\mathrm{~L} 7)_{3}\right]^{9+}\right) \cdot{ }^{[21]}$ In the presence of excess ligand (Ln:L7 $<1.0$ ), we observe the formation of a new species ascribed to $\left[\mathrm{Ln}_{2}(\mathrm{~L} 7)_{3}\right]^{6+}$, which does not interconvert rapidly with $\left[\mathrm{Ln}_{3}(\mathrm{~L} 7)_{3}\right]^{9+}$ on the NMR timescale, and whose ${ }^{1} \mathrm{H}$ NMR signals strongly overlap with those of $\left[\mathrm{Ln}_{3}(\mathrm{~L} 7)_{3}\right]^{9+}$ (Figure $4 \mathrm{~b}$ ). Although a detailed assignment of the point group of symmetry and of the solution structure is precluded by the limited set of individual signals detected for this complex $\left(\left[\mathrm{Ln}_{2}(\mathrm{~L} 7)_{3}\right]^{6+}\right.$ corresponds to a maximum of $50 \%$ of the ligand speciation in a mixture of $\mathrm{L} 7,\left[\operatorname{Ln}_{2}(\mathrm{~L} 7)_{3}\right]^{6+}$ and $\left[\operatorname{Ln}_{3}(\mathrm{~L} 7)_{3}\right]^{9+}$,
Figure S2 in the Supporting Information), the observation of anomalously shielded aromatic signals around $\delta=5.9-$ $6.4 \mathrm{ppm}$ for the diamagnetic complexes $\left[\operatorname{Ln}_{2}(\mathrm{~L} 7)_{3}\right]^{6+}(\mathrm{Ln}=$ $\mathrm{La}, \mathrm{Lu}$, Figure 4b) is characteristic for the helication of the strands, which puts $\mathrm{H} 5$ and $\mathrm{H} 6$ in the shielding region of the wrapped benzimidazole rings. ${ }^{[21,22]}$ We tentatively conclude that the triple-helical arrangement is maintained in solution for $\left[\operatorname{Ln}_{2}(\mathrm{~L} 7)_{3}\right]^{6+}$, which may exist as a mixture of structural isomers in which either one terminal or the central metallic site remains unoccupied. In the presence of excess metal ( $\mathrm{Ln}: \mathrm{L} 7>1.0$ ), the signals of $\mathrm{H} 5$ and $\mathrm{H} 6$ that occur at $\delta=5.88$ and $5.76 \mathrm{ppm}$, respectively, in the triple-helix $\left[\mathrm{La}_{3}(\mathrm{~L} 7)_{3}\right]^{9+}$ (Table 4 below) are shifted toward the "regular" aromatic range $(\delta=7.0-8.5 \mathrm{ppm})$, because the wrapping of the strands is relaxed in $\left[\mathrm{La}_{3}(\mathrm{~L} 7)_{2}\right]^{9+}$ (Figure $4 \mathrm{c}$ ). The broadening of the peaks together with the systematic observation of enantiotopic signals for the methylene probes H12-H12', H13-H13', H14-H14', H15-H15', and H16-H16' point to fast dynamic equilibria compatible with an average $C_{2 v}$ symmetry of the ligand strands, as found for the free ligand. Significant paramagnetic shifts in $\left[\mathrm{Eu}_{3}(\mathrm{~L} 7)_{2}\right]^{9+}$ confirm that the ligands remain coordinated to the metal ions, and these results are compatible with $\left[\mathrm{Ln}_{3}(\mathrm{~L} 7)_{2}\right]^{9+}$ adopting a flexible doublehelical structure in which $P P P \rightleftharpoons M M M$ helical interconversion is fast on the NMR timescale. ESI-MS data strongly suggest that solvent molecules and/or triflate counterions complete the coordination sphere. ${ }^{19} \mathrm{~F}$ NMR spectra of $\left[\mathrm{Lu}_{3}(\mathrm{~L} 7)_{3}\right]^{9+}$ and $\left[\mathrm{Lu}_{3}(\mathrm{~L} 7)_{2}\right]^{9+}$ in $\mathrm{CD}_{3} \mathrm{CN}$ at $298 \mathrm{~K}$ show one singlet corresponding to ionic triflate anions $\left(\delta_{\mathrm{F}}=\right.$ $-79.68 \mathrm{ppm}$ with respect to $\mathrm{CFCl}_{3}$ ), but low-temperature spectra for $\left[\mathrm{Lu}_{3}(\mathrm{~L} 7)_{2}\right]^{9+}$ display signals for both ionic and coordinated triflates, which are involved in partial complexation in the first coordination sphere. In conclusion, NMR data support ESI-MS and spectrophotometric data obtained at lower concentrations and points to the formation of three complexes in solutions: one bimetallic triple-helical complex $\left[\mathrm{Ln}_{2}(\mathrm{~L} 7)_{3}\right]^{6+}$ existing as a mixture of isomers, one rigid and well-defined trimetallic triple-stranded helicate $\left[\mathrm{Ln}_{3}(\mathrm{~L} 7)_{3}\right]^{9+}$, and one dynamically flexible trimetallic double-stranded helicate $\left[\mathrm{Lu}_{3}(\mathrm{~L} 7)_{2}\right]^{9+}$. Since the ultimate goal of our approach is concerned with the design of saturated lanthanide complexes with predetermined properties, only the trimetallic triple-stranded helicates $\left[\operatorname{Ln}_{3}(\mathrm{~L} 7)_{3}\right]^{9+}$ have been further characterized.

Isolation of the complexes: Stoichiometric mixing of $\mathrm{L} 7$ with $\mathrm{Ln}\left(\mathrm{CF}_{3} \mathrm{SO}_{3}\right)_{3} \cdot x \mathrm{H}_{2} \mathrm{O}(\mathrm{Ln}=\mathrm{La}, \mathrm{Eu}, \mathrm{Gd}, \mathrm{Tb}, \mathrm{Lu} ; \times=1-4)$ in acetonitrile followed by slow diffusion of diethyl ether provide microcrystalline powders of $\left[\mathrm{Ln}_{3}(\mathrm{~L} 7)_{3}\right]\left(\mathrm{CF}_{3} \mathrm{SO}_{3}\right)_{9}$. $x \mathrm{H}_{2} \mathrm{O}(\mathrm{Ln}=\mathrm{La}, x=4: 5 ; \mathrm{Ln}=\mathrm{Eu}, x=4: \mathbf{6} ; \mathrm{Ln}=\mathrm{Gd}, x=2$ : 7; $\mathrm{Ln}=\mathrm{Tb}, x=12: 8 ; \mathrm{Ln}=\mathrm{Lu}, x=6: 9)$ in $77-89 \%$ yield. Elemental analyses support the proposed formulations (Table S2 in the Supporting Information) together with the IR spectra, which display the bands characteristics of the ligand strands. Complexation to $\mathrm{Ln}^{\mathrm{III}}$ in $\mathbf{5}-\mathbf{9}$ induces a splitting and a red shift $\left(20 \mathrm{~cm}^{-1}\right)$ of the $v_{\mathrm{C}=\mathrm{O}}$ stretching frequency, while new strong absorptions at $1250\left(v_{\mathrm{s}}+v_{\mathrm{as}}\left(\mathrm{CF}_{3}\right)\right), 1160\left(v_{\mathrm{as}}\left(\mathrm{SO}_{3}\right)\right)$, $1050\left(v_{\mathrm{s}}\left(\mathrm{SO}_{3}\right)\right)$, and $640 \mathrm{~cm}^{-1}\left(v_{\text {as }}\left(\mathrm{SO}_{3}\right)\right)$ are typical for ionic triflate counterions. ${ }^{[30]}$ Re-dissolution of 5-9 in acetonitrile 
gives ${ }^{1} \mathrm{H}$ NMR and ESI-MS spectra identical to those obtained from direct titrations after thermodynamic equilibration. X-ray quality prisms of $\left[\mathrm{Eu}_{3}(\mathrm{~L} 7)_{3}\right]\left(\mathrm{CF}_{3} \mathrm{SO}_{3}\right)_{9}$ $\left(\mathrm{CH}_{3} \mathrm{CN}\right)_{9}\left(\mathrm{H}_{2} \mathrm{O}\right)_{2}(\mathbf{1 0})$ were obtained by slow diffusion of diethyl ether into a concentrated acetonitrile solution of $\mathbf{6}$.

Crystal and molecular structure of $\left[\mathrm{Eu}_{3}\left(\mathrm{L7}_{3}\right)_{3}\right]\left(\mathrm{CF}_{3} \mathrm{SO}_{3}\right)_{9}$. $\left(\mathrm{CH}_{3} \mathbf{C N}\right)_{9} \cdot\left(\mathrm{H}_{2} \mathrm{O}\right)_{2}(\mathbf{1 0})$ : The crystal structure of 10 consists of discrete triple-helical $\left[\mathrm{Eu}_{3}(\mathrm{~L} 7)_{3}\right]^{9+}$ ions, uncoordinated triflate anions, and solvent molecules. The anions and solvent molecules are partially disordered (see CCDC data and Experimental Section). Figure 5 shows the atom-numbering scheme, Figure 6 displays a view of the cation perpendicular to the pseudo-threefold axis, and selected geometrical parameters are collected in Table 2.

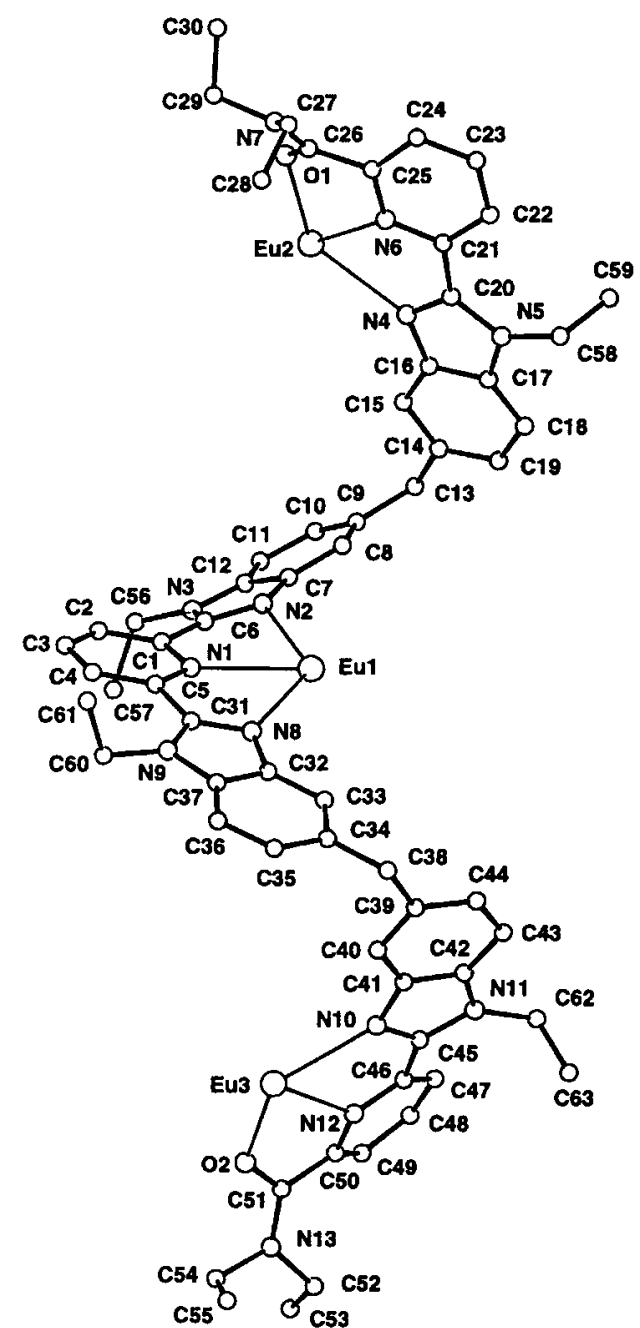

Figure 5. Perspective view of one strand in the cation $\left[\mathrm{Eu}_{3}(\mathrm{~L} 7)_{3}\right]^{9+}$ with the atomic numbering scheme.

The molecular structure of $\left[\mathrm{Eu}_{3}(\mathrm{~L} 7)_{3}\right]^{9+}$ confirms the formation of a triple-stranded helicate, with its pseudothreefold axis passing through the three europium atoms. The helical twist of the ligands results from successive torsions about the interannular $\mathrm{C}-\mathrm{C}$ bonds within each tridentate segments $\left(12-41^{\circ}\right.$, Table S3 in the Supporting Information)

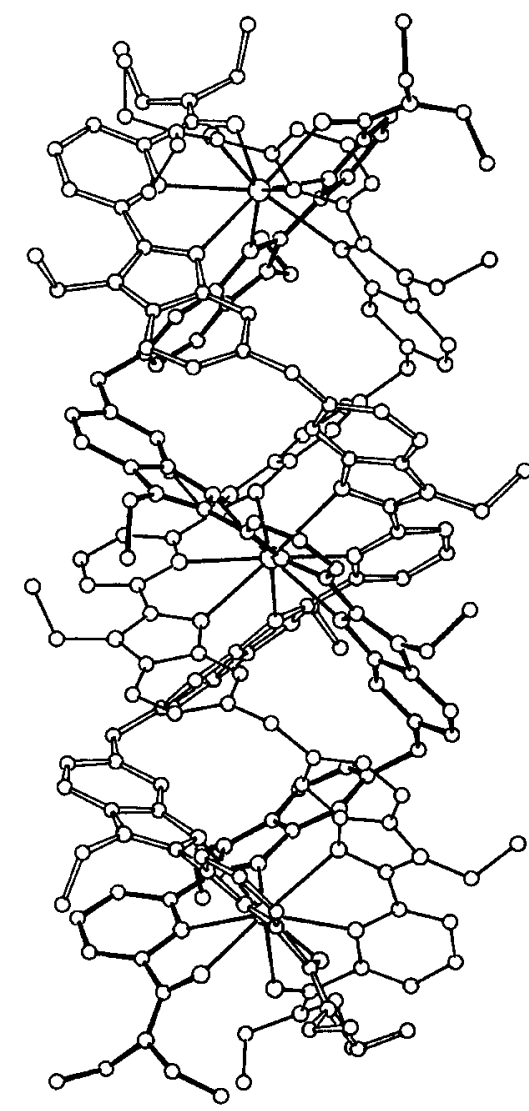

Figure 6. View of the cation $\left[\mathrm{Eu}_{3}(\mathrm{~L} 7)_{3}\right]^{9+}$ perpendicular to the pseudo- $C_{3}$ axis with a different representation for each strand.

Table 2. Selected bond lengths $[\AA]$ and angles $\left[^{\circ}\right]$ for $\left[\mathrm{Eu}_{3^{-}}\right.$ (L7) $\left.)_{3}\right]\left(\mathrm{CF}_{3} \mathrm{SO}_{3}\right)_{9}\left(\mathrm{CH}_{3} \mathrm{CN}\right)_{9}\left(\mathrm{H}_{2} \mathrm{O}\right)_{2}(\mathbf{1 0})$.

\begin{tabular}{lrrr}
\hline & ligand a & ligand b & \multicolumn{1}{c}{ ligand c } \\
\hline Eu1-N1 & $2.607(6)$ & $2.555(7)$ & $2.608(7)$ \\
Eu1-N2 & $2.534(7)$ & $2.593(7)$ & $2.599(6)$ \\
Eu1-N8 & $2.599(7)$ & $2.583(5)$ & $2.585(7)$ \\
Eu2-O1 & $2.381(6)$ & $2.376(6)$ & $2.408(6)$ \\
Eu2-N4 & $2.597(6)$ & $2.549(7)$ & $2.643(7)$ \\
Eu2-N6 & $2.594(7)$ & $2.651(7)$ & $2.653(6)$ \\
Eu3-O2 & $2.375(8)$ & $2.400(7)$ & $2.405(5)$ \\
Eu3-N10 & $2.565(7)$ & $2.665(7)$ & $2.594(7)$ \\
Eu3-N12 & $2.597(7)$ & $2.571(6)$ & $2.565(8)$ \\
Eu1 $\cdots$ Eu2 & $9.3165(7)$ & & \\
Eu1 $\cdots$ Eu3 & $9.0762(7)$ & & \\
Eu2 $\cdots$ Eu3 & $18.3650(9)$ & & \\
N1-Eu1-N2 & $63.7(2)$ & $63.2(2)$ & $63.5(2)$ \\
N1-Eu1-N8 & $62.2(2)$ & $62.4(2)$ & $61.8(2)$ \\
N2-Eu1-N8 & $125.9(2)$ & $125.5(2)$ & $125.2(2)$ \\
O1-Eu2-N6 & $64.5(2)$ & $63.1(2)$ & $63.2(2)$ \\
N4-Eu2-N6 & $62.8(2)$ & $62.6(2)$ & $61.7(2)$ \\
O1-Eu2-N4 & $127.1(2)$ & $125.7(2)$ & $124.9(2)$ \\
N10-Eu3-N12 & $62.6(2)$ & $63.9(2)$ & $63.1(2)$ \\
O2-Eu3-N12 & $63.1(2)$ & $62.7(2)$ & $62.6(2)$ \\
O2-Eu3-N10 & $125.7(2)$ & $125.1(2)$ & $125.6(2)$ \\
Eu2 $\cdots$ Eu1 $\cdots$ Eu3 & $173.71(1)$ & & \\
\hline
\end{tabular}

combined with approximate orthogonal arrangements $(60-$ $87^{\circ}$, average $76^{\circ}$ ) of the benzimidazole rings connected to the same methylene spacer (Figure 6). The total length of a helical strand in $\left[\mathrm{Eu}_{3}(\mathrm{~L} 7)_{3}\right]^{9+}$ amounts to $21.6 \AA$ [as measured by the distance between the facial planes (F1 and F9) defined by the 
terminal oxygen atoms F1: O2a, O2b, O2c and F9: O1a, O1b, O1c, Scheme 2] for 1.58 turns, thus leading to an average pitch of $13.6 \AA$. A detailed analysis of each helical portion defined by the nine almost parallel facial planes F1-F9 (Scheme 2,

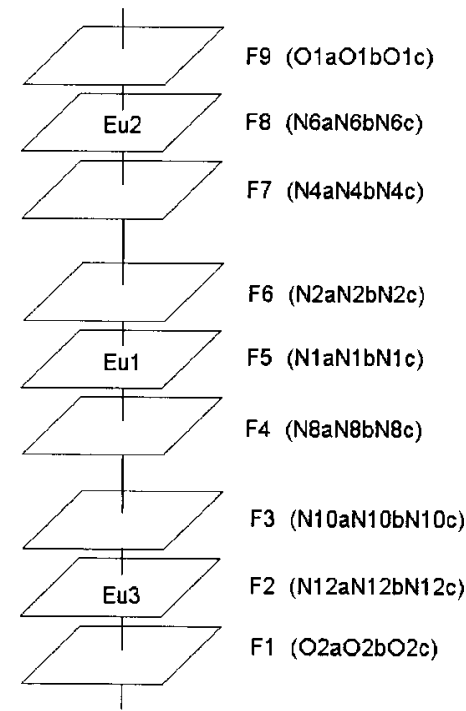

Scheme 2. Facial planes $\mathrm{F} 1-\mathrm{F} 9$ delimiting the helical portions in $\left[\mathrm{Eu}_{3^{-}}\right.$$\left.(\mathrm{L} 7)_{3}\right]^{9+}$.

interplanar angles $1-18^{\circ}$, Table S4 in the Supporting Information) requires the calculation of specific helical pitches $P_{i j}=d(\mathrm{~F} i-\mathrm{F} j) /\left(\omega_{i j} / 360\right)$ for each $\mathrm{F} i-\mathrm{F} j$ portion, in which $d(\mathrm{~F} i-\mathrm{F} j)$ is the separation between the facial planes and $\omega_{i j}$ is the average twist angle defined by the angular rotation between the projections of $\mathrm{N} i$ and $\mathrm{N} j$ (or $\mathrm{O} j$ ) belonging to the same ligand strand (Tables S5-S7 in the Supporting Information). ${ }^{[31]}$ The resulting $P_{i j}$ values collected in Table 3 correspond to the length of cylinders containing a single turn of the helices defined by the geometrical $d(\mathrm{~F} i-\mathrm{F} j)$ and $\omega_{i j}$ parameters. Significant variations of the wrapping mode of the ligands occur along the helical axis. Firstly, the helicity within the terminal $\mathrm{EuN}_{6} \mathrm{O}_{3}$ sites is irregular with tight rotation characterizing the carboxamide-pyridine units $\left(P_{12}=9.03\right.$ and $\left.P_{89}=9.38 \AA\right)$ followed by smaller angular rotation (i.e., larger pitches) for the pyridine-benzimidazole

Table 3. Helical pitches $P_{i j}$, linear distances $d(\mathrm{~F} i-\mathrm{Fj})$ and average twist angles $\omega_{i j}$ along the pseudo- $C_{3}$ axis in the crystal structure of $\left[\mathrm{Eu}_{3}\right.$ $\left.(\mathrm{L} 7)_{3}\right]\left(\mathrm{CF}_{3} \mathrm{SO}_{3}\right)_{9} \cdot\left(\mathrm{CH}_{3} \mathrm{CN}\right)_{9} \cdot\left(\mathrm{H}_{2} \mathrm{O}\right)_{2}(\mathbf{1 0})$.

\begin{tabular}{llcr}
\hline & $d(\mathrm{Fi}-\mathrm{Fj})[\AA]$ & $\omega_{i j}{ }^{[\mathrm{a}]}\left[{ }^{\circ}\right]$ & $P_{i j}[\AA]$ \\
\hline $\mathrm{F} 1-\mathrm{F} 2^{[\mathrm{b}]}$ & 1.42 & 56.6 & 9.03 \\
$\mathrm{~F} 2-\mathrm{F} 3$ & 50.1 & 13.37 \\
$\mathrm{~F} 3-\mathrm{F} 4$ & 1.86 & 123.1 & 17.00 \\
F4-F5 & 5.81 & 54.1 & 10.45 \\
F5-F6 & 1.57 & 53.6 & 11.35 \\
F6-F7 & 1.69 & 122.4 & 17.97 \\
F7-F8 & 6.11 & 51.7 & 11.84 \\
F8-F9 & 1.70 & 56.4 & 9.38
\end{tabular}

[a] $\omega_{i j}$ are given as $C_{3}$-average values (see Tables S5-S7 for the definition of $\omega_{i j}$ in the Supporting Information). [b] F1: O2a, O2b, O2c; F2: N12a, N12b, N12c; F3: N10a, N10b, N10c; F4: N8a, N8b, N8c; F5: N1a, N1b, N1c; F6: N2a, N2b, N2c; F7: N4a, N4b, N4c; F8: N6a, N6b, N6c; F9: O1a, O1b, O1c (see Scheme 2). portions $\left(P_{23}=13.37\right.$ and $\left.P_{78}=11.84 \AA\right)$. A parallel behavior has been previously reported for heterobimetallic triplestranded $\mathrm{LnCr}^{\mathrm{III}}$ helicates in which $\mathrm{Ln}^{\mathrm{III}}$ is coordinated by similar terminal tridentate NNO binding units. ${ }^{[18]}$ Despite the use of rigid diphenylmethane spacers between the ninecoordinate metallic sites, the helical twist is severely relaxed in the intermetallic portions of the triple helix (F3/F4 and F6/ F7), while a tighter rotation is associated with the complexation of the central bis(benzimidazole)pyridine segments to Eu1 (F4/F5 and F5/F6).

No significant interstrand stacking interaction is detected in $\left[\mathrm{Eu}_{3}(\mathrm{~L} 7)_{3}\right]^{9+}$ and the stability of the final helicate relies on the formation of 27 dative bonds ( $21 \mathrm{Eu}-\mathrm{N}$ and $6 \mathrm{Eu}-\mathrm{O}$ bonds) that overcome the electrostatic repulsion associated with three $\mathrm{Eu}^{\mathrm{III}}$ held at approximately $9.0 \AA$ (Table 2 ). In contrast to the molecular structure of the monometallic model compound $\left[\mathrm{Eu}(\mathrm{L} 9)_{3}\right]^{3+}$, in which strong interstrand $\pi-\pi$ stacking interactions between the imidazole rings prevent complexation of small $\mathrm{Ln}^{\mathrm{III}},{ }^{[25,32]}$ stereochemical constraints induced by the terminal metallic sites in $\left[\mathrm{Eu}_{3}(\mathrm{~L} 7)_{3}\right]^{9+}$ affect the wrapping of the strands around Eu1. Interstrand interactions are removed in $\left[\mathrm{Eu}_{3}(\mathrm{~L} 7)_{3}\right]^{9+}$ and this may explain the lack of size-discriminating effects affecting $\beta_{33}$ along the lanthanide series (Table 1). The three metals are ninecoordinate surrounded by three wrapped tridentate segments leading to slightly distorted tricapped trigonal prisms in which the three nitrogen atoms of the pyridine rings occupy the capping positions. Detailed geometrical analyses based on the $\phi, \theta_{i}$ and $\omega_{i j}$ angles (Tables S5-S7 in the Supporting Information $)^{[33]}$ show only minor deformations from perfect trigonal prisms, except for small twists of the trigonal faces $\left(\omega_{i j}=9-\right.$ $15^{\circ}$ ) that closely match those reported for the model compounds $\left[\mathrm{Eu}(\mathrm{L} 9)_{3}\right]^{3+}\left(\omega_{i j}=10^{\circ}\right)^{[32]}$ and $\left[\mathrm{Eu}(\mathrm{L} 10)_{3}\right]^{3+}\left(\omega_{i j}=\right.$ $\left.15-17^{\circ}\right) .{ }^{[33]}$ The only significant differences between the<smiles>CCN(CC)C(=O)c1cccc(C(=O)N(CC)CC)n1</smiles>

geometry of the terminal and the central metallic sites are the slight shifts of Eu2 and Eu3 out of the facial planes F8 $(0.148(1) \AA)$ and F2 (0.191(1) $\AA$ ) toward the oxygen tripods, while Eu1 lies in the facial plane F5 (deviation 0.0023(1) $\AA$ ). The $\mathrm{Eu}-\mathrm{N}($ benzimidazole), $\mathrm{Eu}-\mathrm{N}$ (pyridine), and $\mathrm{Eu}-\mathrm{O}-$ (amide) bond lengths are standard (Table 2), ${ }^{[13,14]}$ although considerable bending of the pyridine and benzimidazole rings preclude ideal alignments of the nitrogen lone pairs with the coordinated $\mathrm{Eu}^{\mathrm{III}}$ ion (Figure 6). We conclude that the replacement of heterocyclic nitrogen atoms in NNN segments with oxygen atoms in NNO segments has minor effects on the geometrical arrangement of the nine-coordinate pseudotricapped trigonal prismatic metallic sites, but the stronger (and shorter) $\mathrm{Eu}-\mathrm{O}$ bonds reinforce the nonequivalence of the coordination sites along the helix. 
In the crystals, the triple helical cations are closely packed parallel with the $b c$ plane with their pseudo-threefold axis almost aligned $\left(4.6^{\circ}\right)$ with the [01 $\left.\overline{2}\right]$ direction (Figure S3 in the Supporting Information).

Multicenter paramagnetic NMR spectra and solution structure of $\left[\mathbf{L n}_{\mathbf{3}}(\mathbf{L 7})_{\mathbf{3}}\right]^{\mathbf{9}+}(\mathbf{L n}=\mathbf{L a}-\mathbf{T b}, \mathbf{Y}, \mathbf{L u})$ : The ${ }^{1} \mathrm{H}$ NMR spectra of $\left[\mathrm{Ln}_{3}(\mathrm{~L} 7)_{3}\right]^{9+}$ for the diamagnetic metals $\mathrm{Ln}=\mathrm{La}, \mathrm{Y}$, $\mathrm{Lu}$ display 25 well-resolved signals assigned to eleven aromatic protons $(\mathrm{H} 1-\mathrm{H} 11)$, ten methylene protons $(\mathrm{H} 12-$ H16), and four methyl groups (Me17-Me20) characteristic of a half ligand strand and pointing to average $D_{3}, D_{3 h}$, or $C_{3 h}$ symmetry for the complexes in solution (Figure 4a). The systematic diastereotopicity of all methylene protons (H12H16) (observed as pseudo-sextets because $J^{2} \approx 2 J^{3}$, Figure 4a) excludes a $D_{3 h}$ symmetrical arrangement of the three strands (i.e., a nonhelical arrangement or a fast helical interconversion), but it is compatible with a non-interconverting racemic mixture of 1) helicates $P P P-\left[\operatorname{Ln}_{3}(\mathrm{~L} 7)_{3}\right]^{9+}$ and $M M M$ $\left[\mathrm{Ln}_{3}(\mathrm{~L} 7)_{3}\right]^{9+}$ or 2$)$ side-by-side complexes $P M P-\left[\mathrm{Ln}_{3}(\mathrm{~L} 7)_{3}\right]^{9+}$ and $M P M-\left[\operatorname{Ln}_{3}(\mathrm{~L} 7)_{3}\right]^{9+}$ belonging to the $D_{3}$ point group. ${ }^{[34]}$ The large upfield complexation shifts of the protons bound to the 4-position of the benzimidazole rings $(\mathrm{H} 5, \mathrm{H} 6)$ in $\left[\mathrm{La}_{3}(\mathrm{~L} 7)_{3}\right]^{9+}(\Delta \delta=1.83-1.93 \mathrm{ppm}),\left[\mathrm{Y}_{3}(\mathrm{~L} 7)_{3}\right]^{9+}(\Delta \delta=2.21-$ $2.37 \mathrm{ppm})$, and $\left[\mathrm{Lu}_{3}(\mathrm{~L} 7)_{3}\right]^{9+}(\Delta \delta=2.32-2.50 \mathrm{ppm}$, Table 4) are diagnostic for a regular helication that puts these protons in the shielding region of the connected benzimidazole ring ${ }^{[22]}$ in agreement with the crystal structure of $\left[\mathrm{Eu}_{3}(\mathrm{~L} 7)_{3}\right]^{9+}$ (Figure 6), but in complete contradiction with amphiverse $P M P$ (or $M P M$ ) conformers. The observation of weak but significant interstrand NOE effects involving protons of the terminal and central binding units (for instance $\mathrm{H} 4-\mathrm{H} 18$ ) points to three strands tightly wrapped about the helical axis; ${ }^{[22]}$ this rules out complexes that possess a central lanthanide with no helicity such as the racemic mixture of $P P-\left[\operatorname{Ln}_{3}(\mathrm{~L} 7)_{3}\right]^{9+}$ and $M M-\left[\operatorname{Ln}_{3}(\mathrm{~L} 7)_{3}\right]^{9+}\left(D_{3}\right.$ symmetry $)$ or the side-by-side complex $P M$ - $\left[\operatorname{Ln}_{3}(\mathrm{~L} 7)_{3}\right]^{9+}\left(C_{3 h}\right.$ symmetry). These NMR data unambiguously establish that the triple-helical structure observed in the solid state is maintained in solution along the complete lanthanide series and that relaxation of intermolecular constraints provides a racemic mixture of inert triple-stranded helicates $P P P-\left[\mathrm{Ln}_{3}(\mathrm{~L} 7)_{3}\right]^{9+}$ and $M M M-$ $\left[\operatorname{Ln}_{3}(\mathrm{~L} 7)_{3}\right]^{9+}$ with average $D_{3}$ symmetry on the NMR timescale.

Further geometrical and electronic information can be gained from the separation of contact (through-bond, $\delta_{i j}^{c}$ ) and pseudo-contact (through-space, $\delta_{i j}^{\mathrm{pc}}$ ) contributions to the isotropic paramagnetic shifts $\left(\delta_{i j}^{\text {para }}\right)$ produced by fast-relaxing $\mathrm{Ln}^{\mathrm{III}} \cdot{ }^{[35]}$ For any nucleus $i$ in a complex of a lanthanide $j$, the paramagnetic shifts are obtained from the experimental chemical shifts $\delta_{i j}^{\text {exptl }}$ by using Equation (6) if the residual signal of the solvent is taken as an internal reference. ${ }^{[35,36]}$ The diamagnetic contribution $\delta_{i j}^{\mathrm{dia}}$ in the paramagnetic complexes $\left[\operatorname{Ln}_{3}(\mathrm{~L} 7)_{3}\right]^{9+}$ is obtained from the NMR spectra of the isostructural diamagnetic complexes $\left[\mathrm{La}_{3}(\mathrm{~L} 7)_{3}\right]^{9+}(\mathrm{Ln}=\mathrm{Ce}-$ $\mathrm{Nd}),\left[\mathrm{Y}_{3}(\mathrm{~L} 7)_{3}\right]^{9+}(\mathrm{Ln}=\mathrm{Sm}-\mathrm{Ho})$ and $\left[\mathrm{Lu}_{3}(\mathrm{~L} 7)_{3}\right]^{9+}(\mathrm{Ln}=\mathrm{Er}-$ $\mathrm{Yb})$.

$\delta_{i j}^{\mathrm{para}}=\delta_{i j}^{\mathrm{c}}+\delta_{i j}^{\mathrm{pc}}=\delta_{i j}^{\mathrm{exptl}}-\delta_{i j}^{\mathrm{dia}}$

The contact contribution results from spin delocalization according to the Fermi mechanism [Eq. (7)] in which $F_{i}$ is the contact term (proportional to the hyperfine Fermi constant $\left.A_{i}\right)$ and $\left\langle S_{z}\right\rangle_{j}$ is the spin expectation value of the $S_{z}$ operator tabulated by Golding and Halton for the free lanthanide ions at $300 \mathrm{~K} .^{[37]}$

$\delta_{i j}^{\mathrm{c}}=\frac{A_{i}}{\hbar \gamma_{\mathrm{I}} H_{0}}\left\langle S_{z}\right\rangle_{j}=F_{i}\left\langle S_{z}\right\rangle_{j}$

For axial complexes possessing at least a threefold axis, the development of the paramagnetic anisotropy of lanthanide complexes in a power series of $T^{-n}$ limited to $n=2$ proposed by Bleaney ${ }^{[38]}$ leads to Equation (8) for the pseudo-contact contribution, in which $B_{0}^{2}$ is the second-rank crystal-field parameter of the complex, $C_{j}$ is the Bleaney's factor tabulated for each lanthanide $j$ at $300 \mathrm{~K}$ and scaled to $C_{\mathrm{Dy}}=-100^{[35,38]}$ and $G_{i}=\left(3 \cos ^{2}\left(\theta_{i}\right)-1\right) / r_{i}^{3}$ is the structural factor of the nucleus $i$ containing its internal axial coordinates $\theta_{i}$ and $r_{i}$.

$\delta_{i j}^{\mathrm{pc}}=-\frac{\beta^{2}\left(1+p_{j}\right) \zeta_{\mathrm{j}}}{120(k T)^{2}}\left[B_{0}^{2}\left(\frac{3 \cos ^{2} \theta_{\mathrm{i}}-1}{r_{i}^{3}}\right)\right]=C_{j} B_{0}^{2} G_{i}$

Table 4. Experimental and computed ${ }^{1} \mathrm{H}$ NMR shifts (in ppm with respect to $\mathrm{SiMe}_{4}$ ) for $\left[\mathrm{Ln}_{3}(\mathrm{~L} 7)_{3}\right]^{9+}$ in $\mathrm{CD}_{3} \mathrm{CN}$ at $298 \mathrm{~K}$. [a]

\begin{tabular}{|c|c|c|c|c|c|c|c|c|c|c|c|c|c|c|c|}
\hline & $\mathrm{H} 1$ & $\mathrm{H} 2$ & $\mathrm{H} 3$ & $\mathrm{H} 4$ & H5 & H6 & $\mathrm{H} 7$ & H8 & H9 & H10 & H11 & Me17 & Me18 & Me19 & Me20 \\
\hline L7 & 8.00 & 8.30 & 7.33 & 7.22 & 7.71 & 7.69 & 7.22 & 7.34 & 8.37 & 7.91 & 7.51 & 1.31 & 1.42 & 1.25 & 1.04 \\
\hline$\left[\mathrm{La}_{3}(\mathrm{~L} 7)_{3}\right]^{9+}$ & 8.09 & 7.64 & 7.19 & 6.92 & 5.88 & 5.76 & 7.24 & 7.53 & 8.20 & 8.18 & 7.60 & 1.42 & 1.39 & 0.90 & 0.65 \\
\hline$\left[\mathrm{Y}_{3}(\mathrm{~L} 7)_{3}\right]^{9+}$ & 7.92 & 7.55 & 7.22 & 6.87 & 5.50 & 5.32 & 7.19 & 7.51 & 8.27 & 8.17 & 7.65 & 1.46 & 1.44 & 1.01 & 0.59 \\
\hline$\left[\mathrm{Lu}_{3}(\mathrm{~L} 7)_{3}\right]^{9+}$ & 7.88 & 7.53 & 7.24 & 6.89 & 5.39 & 5.19 & 7.16 & 7.50 & 8.28 & 8.17 & 7.66 & 1.45 & 1.44 & 1.04 & 0.58 \\
\hline$\left[\mathrm{Ce}_{3}(\mathrm{~L} 7)_{3}\right]^{9+}$ & 8.71 & 8.19 & 7.14 & 6.27 & -2.17 & -2.40 & 6.79 & 7.47 & 10.27 & 9.78 & 8.87 & 2.46 & 1.78 & 1.05 & -2.44 \\
\hline$\left[\mathrm{Ce}_{3}(\mathrm{~L} 7)_{3}\right]^{9+[\mathrm{b}]}$ & 8.75 & 8.27 & 7.13 & 6.28 & -2.13 & -2.42 & 6.78 & 7.46 & 10.18 & 9.72 & 8.82 & 2.43 & 1.75 & 1.07 & -2.43 \\
\hline$\left[\operatorname{Pr}_{3}(\mathrm{~L} 7)_{3}\right]^{9+}$ & 9.63 & 9.73 & 7.21 & 5.77 & -8.75 & -9.60 & 6.39 & 7.78 & 11.76 & 10.62 & 9.68 & 3.09 & 2.00 & 1.27 & -4.74 \\
\hline$\left[\mathrm{Nd}_{3}(\mathrm{~L} 7)_{3}\right]^{9+}$ & 9.43 & 9.80 & 7.51 & 6.29 & -1.31 & -2.73 & 6.79 & 8.16 & 10.51 & 9.57 & 9.12 & 2.10 & 1.12 & 1.12 & -2.00 \\
\hline$\left[\mathrm{Nd}_{3}(\mathrm{~L} 7)_{3}\right]^{9+[\mathrm{b}]}$ & 9.23 & 9.67 & 7.54 & 6.33 & -1.20 & -2.15 & 6.82 & 8.48 & 10.60 & 9.49 & 9.03 & 2.15 & 1.59 & 1.07 & -1.83 \\
\hline$\left[\mathrm{Eu}_{3}(\mathrm{~L} 7)_{3}\right]^{9+}$ & 6.21 & 4.17 & 6.35 & 7.62 & 13.10 & 14.04 & 7.76 & 4.50 & 4.76 & 6.35 & 5.24 & 0.71 & 0.84 & 0.53 & 3.61 \\
\hline$\left[\mathrm{Eu}_{3}(\mathrm{~L} 7)_{3}\right]^{9+[\mathrm{b}]}$ & 5.66 & 2.95 & 6.23 & 7.71 & 15.14 & 16.96 & 7.79 & 4.93 & 4.18 & 6.45 & 5.27 & 0.67 & 1.32 & 0.75 & 3.67 \\
\hline$\left[\mathrm{Eu}_{3}(\mathrm{~L} 7)_{3}\right]^{9+[\mathrm{c}]}$ & 6.14 & 4.05 & 6.48 & 7.60 & 13.90 & 15.20 & 7.71 & 5.54 & 4.90 & 6.62 & 5.66 & 0.71 & 1.26 & 0.77 & 3.39 \\
\hline$\left[\mathrm{Tb}_{3}(\mathrm{~L} 7)_{3}\right]^{9+}$ & 8.86 & -3.14 & 1.42 & 0.12 & -80.00 & -75.00 & 2.27 & -5.56 & 20.20 & 25.20 & 16.80 & 13.91 & 5.80 & 3.50 & -36.50 \\
\hline$\left[\mathrm{Tb}_{3}(\mathrm{~L} 7)_{3}\right]^{9+[\mathrm{b}]}$ & 8.60 & -2.81 & 1.83 & 0.03 & -83.33 & -77.44 & 2.35 & -5.14 & 22.55 & 25.74 & 17.14 & 14.54 & 6.88 & 2.68 & -36.30 \\
\hline
\end{tabular}

[a] $\mathrm{Sm}^{\mathrm{III}}$ is not considered because of its weak paramagnetism. [b] Chemical shifts calculated with Equation $(11)$ and $\left\langle S_{z}\right\rangle_{j}=10.68$ (see text). [c] Chemical shifts calculated with Equation (11) and $\left\langle S_{z}\right\rangle_{j}=7.5$ (see text). 
Substituting Equation (7) and (8) into Equation (6) gives Equation (9), which is well suited for extracting contact $\left(F_{i}\right)$ and pseudo-contact $\left(B_{0}^{2} G_{i}\right)$ terms for any nucleus by a multilinear least-squares fit of $\delta_{i j}^{\text {para }}$ versus $\left\langle S_{z}\right\rangle_{j}$ and $C_{j}$ along a series of isostructural monometallic lanthanide complexes, ${ }^{[39]}$ for which the hyperfine constants and the crystalfield parameter do not vary. ${ }^{[17]}$

$\delta_{i j}^{\text {para }}=F_{i}\left\langle S_{z}\right\rangle_{j}+C_{j} B_{0}^{2} G_{i}$

The existence of three paramagnetic centers in the homotrimetallic helicates $\left[\operatorname{Ln}_{3}(\mathrm{~L} 7)_{3}\right]^{9+}$ requires some modifications of the classical Equation (9) derived for monometallic complexes; Equation (10) holds for an axial multicenter homopolymetallic lanthanide complex containing $n$ paramagnetic centers.

$\delta_{i j}^{\text {para }}=\left(\sum_{m=1}^{n} F_{i}^{m}\right)\left\langle S_{z}\right\rangle_{j}+\left(\sum_{m=1}^{n} B_{0}^{2 \mathrm{~m}} G_{i}^{m}\right) C_{j}$

Since 1) no magnetic coupling occurs at room temperature between the $\mathrm{Ln}^{\mathrm{III}}$ ions lying at distances larger than $4 \AA^{[40]}$ and 2) the tridentate binding units are separated by methylene bridges in L7 that are poor electronic relays, we assume that the contact contributions $\delta_{i j}^{c}$ result from through-bond Fermi interactions with a single metallic center as previously demonstrated for $\left[\operatorname{Ln}_{2}(\mathrm{~L} 3-2 \mathrm{H})_{3}\right]^{\left[{ }^{[15]}\right.}$ On the other hand, the pseudo-contact contribution $\delta_{i j}^{\mathrm{pc}}$ in the $D_{3}$-symmetrical helicates $\left[\operatorname{Ln}_{3}(\mathrm{~L} 7)_{3}\right]^{9+}$ results from the sum of the effect induced by each metal ion according to Scheme 3 . Different crystalfield parameters for the central $\operatorname{LnN}_{9}\left(B_{0}^{2^{\text {central }}}\right)$ and the two

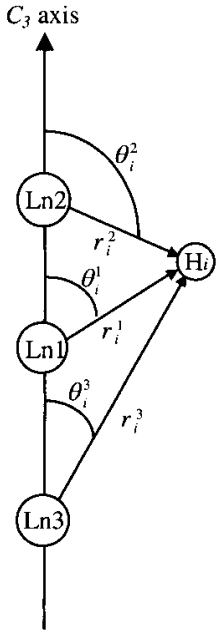

Scheme 3. Axial coordinates considered in the trimetallic axial complexes $\left[\mathrm{Ln}_{3}(\mathrm{~L} 7)_{3}\right]^{9+}$.

terminal $\mathrm{LnN}_{6} \mathrm{O}_{3}\left(B_{0}^{2^{\text {terminal }}}\right)$ metallic sites are required and Equation (10) reduces to Equation (11) for $\left[\operatorname{Ln}_{3}(\mathrm{~L} 7)_{3}\right]^{9+}$ with $S_{\mathrm{i}}$ defined as $\left[B_{0}^{2^{\text {central }}} G_{i}^{1}+B_{0}^{\text {terminal }}\left(G_{i}^{2}+G_{i}^{3}\right)\right]$.

$\delta_{i j}^{\text {para }}=F_{i}\left\langle S_{z}\right\rangle_{j}+C_{j} S_{i}$

The associated linear forms [Eqs. (12) and (13)] can be used for testing isostructurality, since plots of $\delta_{i j}^{\text {para }} /\left\langle S_{z}\right\rangle_{j}$ versus $C_{j} /$ $\left\langle S_{z}\right\rangle_{j}$ [Eq. (12)] and $\delta_{i j}^{\text {para }} / C_{j}$ versus $\left\langle S_{z}\right\rangle_{j} / C_{j}$ [Eq. (13)] are expected to give linear correlations as long as the structural factors $G_{i}^{m}(m=1-3)$, the contact term $F_{i}$, and the crystalfield parameters do not change along the lanthanide series. ${ }^{[17,39]}$

$\frac{\delta_{i j}^{\text {para }}}{\left\langle S_{z}\right\rangle j}=F_{i}+S_{i} \frac{C_{j}}{\left\langle S_{z}\right\rangle j}$

$\frac{\delta_{i j}^{\text {para }}}{C_{j}}=S_{i}+F_{i} \frac{\left\langle S_{z}\right\rangle j}{C_{j}}$

For paramagnetic $\left[\mathrm{Ln}_{3}(\mathrm{~L} 7)_{3}\right]^{9+}$ helicates, a reliable assignment of the $25{ }^{1} \mathrm{H}$ NMR signals depends on the detection of ${ }^{1} \mathrm{H}-{ }^{1} \mathrm{H}$ scalar (from COSY spectra) and dipolar couplings (from NOESY or ROESY spectra). ${ }^{[35]}$ Since lanthanideinduced paramagnetic nuclear relaxation increases with the effective magnetic moments of the complexes, ${ }^{[35]}$ useful COSY and NOESY spectra for fast-relaxing lanthanides can be recorded only for weakly paramagnetic complexes $(\mathrm{Ln}=$ $\mathrm{Ce}, \mathrm{Pr}, \mathrm{Nd}, \mathrm{Sm}$, and Eu, Table 4). For the diastereotopic methylene protons $(\mathrm{H} 12-\mathrm{H} 16)$, the multiplets cannot be assigned unambiguously to one specific proton of the pair along the lanthanide series, and these signals are not considered in the structural analysis. ${ }^{[36]}$ Plots of $\delta_{i j}^{\text {para }} /\left\langle S_{z}\right\rangle_{j}$ versus $C_{j} /\left\langle S_{z}\right\rangle_{j}$ [Eq. (12)] and $\delta_{i j}^{\text {para }} / C_{j}$ versus $\left\langle S_{z}\right\rangle_{j} / C_{j}$ [Eq. (13)] are linear for all aromatic protons $(\mathrm{H} 1-\mathrm{H} 11)$ and for the methyl groups (Me17-Me20) along the series $\mathrm{Ln}=\mathrm{Ce}-\mathrm{Eu}$, in agreement with the existence of an isostructural series (Figure 7). A first set of $F_{i}$ and $S_{i}$ factors obtained with Equation (11) have been used for the prediction of the ${ }^{1} \mathrm{H}$ NMR spectra of $\left[\operatorname{Ln}_{3}(\mathrm{~L} 7)_{3}\right]^{9+}$ with the strongly paramagnetic lanthanides $(\mathrm{Ln}=\mathrm{Tb}-\mathrm{Yb}) \cdot{ }^{[41]}$ Comparison between predictions and experimental data is only satisfying for $\left[\mathrm{Tb}_{3}(\mathrm{~L} 7)_{3}\right]^{9+}$, thus allowing a complete assignment for this complex (Table 4) and its consideration for the calculations of
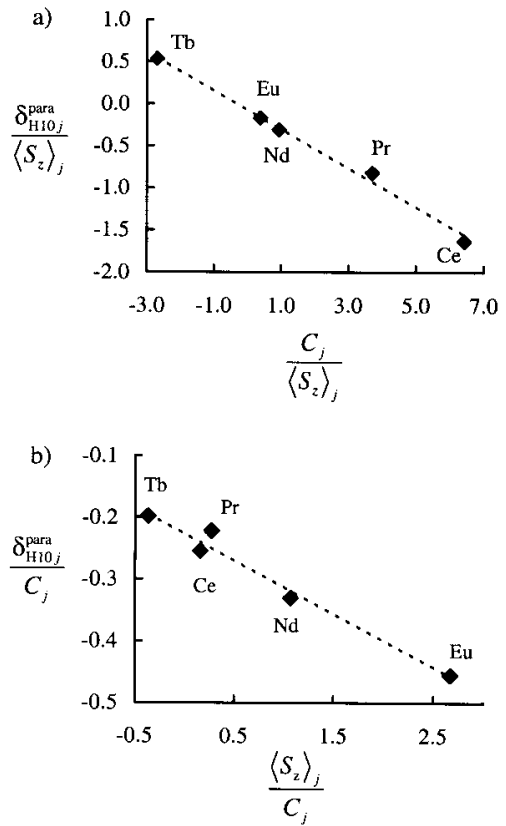

Figure 7. Plots of a) $\delta_{i j}^{\text {para }} /\left\langle S_{z}\right\rangle_{j}$ versus $C_{j} /\left\langle S_{z}\right\rangle_{j}$ [Eq. (12)] and $\delta_{i j}^{\text {para }} / C_{j}$ versus $\left\langle S_{z}\right\rangle_{j} / C_{j}$ [Eq. (13)] for $\mathrm{H} 10$ in $\left[\mathrm{Ln}_{3}(\mathrm{~L} 7)_{3}\right]^{9+}\left(\mathrm{R}=\mathrm{Ce}-\mathrm{Tb}, \mathrm{CD}_{3} \mathrm{CN}, 298 \mathrm{~K}\right)$. 
Table 5. Computed values for contact $\left(F_{i}\right)$ and pseudo-contact $S_{i}=\left[B_{0}^{2^{\text {central }}} G_{i}^{1}+B_{0}^{2^{\text {terminal }}}\left(G_{i}^{2}+G_{i}^{3}\right)\right]$ terms and agreement factors $\left(A F_{i}\right)$ for aromatic and methyl protons in complexes $\left[\mathrm{Ln}_{3}(\mathrm{~L} 7)_{3}\right]^{9+}\left(\mathrm{Ln}=\mathrm{Ce}-\mathrm{Tb}, \mathrm{CD}_{3} \mathrm{CN}, 298 \mathrm{~K}\right) \cdot{ }^{[\mathrm{a}]}$

\begin{tabular}{|c|c|c|c|c|c|c|c|c|c|c|c|c|c|c|c|}
\hline & H1 & $\mathrm{H} 2$ & H3 & $\mathrm{H} 4$ & H5 & H6 & $\mathrm{H} 7$ & H8 & H9 & $\mathrm{H} 10$ & H11 & Me17 & Me18 & Me19 & $\mathrm{Me} 20$ \\
\hline & $-0.18(3)$ & $-0.42(6)$ & $-0.10(1)$ & $.043(4)$ & $0.45(7)$ & $0.6(1)$ & $0.031(3)$ & $-0.26(3)$ & -0.2 & -0. & -0 & -0 & $0.01(4)$ & -0 & $0.11(2)$ \\
\hline$S_{i}$ & $-0.08(1)$ & $-0.03(2)$ & $0.025(2)$ & $0.095(1)$ & $1.20(2)$ & $1.20(3)$ & $0.068(1)$ & $0.05(1)$ & $-0.27(1)$ & $-0.23(1)$ & $-0.17(1)$ & $-0.158(4)$ & $-0.06(1)$ & $-0.025(4)$ & $0.470(5)$ \\
\hline$A F_{i}^{[\mathrm{b}]}$ & 0.23 & 0.12 & 0.07 & 0.02 & 0.04 & 0.05 & 0.02 & 0.05 & 0.18 & 0.04 & 0.04 & 0.05 & 0.29 & 0.33 & 0.01 \\
\hline
\end{tabular}

[a] $F_{i}$ and $S_{i}$ are obtained by linear least-squares fits of $\delta_{i j}^{\text {para }} /\left\langle S_{z}\right\rangle_{j}$ versus $C_{j}\left\langle\left\langle S_{z}\right\rangle_{j}\right.$ [Eq. (12)]. [b] Calculated according to $A F_{i}=\left[\sum_{j}\left(\delta_{i j}^{\text {obs }}-\delta_{i j}^{\text {calcd }}\right)^{2} / \sum_{j}\left(\delta_{i j}^{\text {obs }}\right)^{2}\right]^{1 / 2 .[44]}$

the final set of $F_{i}$ and $S_{i}$ factors collected in Table 5. For $\mathrm{Ln}=$ $\mathrm{Dy}-\mathrm{Yb}$, the experimental ${ }^{1} \mathrm{H}$ NMR spectra do not fit those predicted with Equation (11), but we cannot ascribe this deviation to an abrupt structural change, since variations of the crystal-field parameters near the middle of the lanthanide series, sometimes referred to as the gadolinium break effect, ${ }^{[41]}$ are likely to occur in $\left[\operatorname{Ln}_{3}(\mathrm{~L} 7)_{3}\right]^{9+}$, as previously observed for related homo- and heteropolymetallic triplestranded helicates. ${ }^{[17,41]}$ More sophisticated mathematical analyses using novel crystal-field independent techniques ${ }^{[36,42]}$ extended to trimetallic complexes with different crystal-field parameters will be discussed elsewhere, ${ }^{[43]}$ but they eventually confirm isostructurality along the complete lanthanide series for $\left[\mathrm{Ln}_{3}(\mathrm{~L} 7)_{3}\right]^{9+}(\mathrm{Ln}=\mathrm{Ce}-\mathrm{Yb})$, together with an abrupt variation of the crystal-field parameters between $\mathrm{Tb}$ and $\mathrm{Dy}$.

For the $\mathrm{Ln}=\mathrm{Ce}-\mathrm{Tb}$ series, the Wilcott agreement factors $^{[44]}$ are acceptable for all aromatic protons $\left(0.02<A F_{i}<\right.$ 0.23 , Table 5), and they can be compared to similar mathematical treatments applied to the monometallic model complexes $\left[\mathrm{Ln}(\mathrm{L} 9)_{3}\right]^{3+}\left(0.04<A F_{i}<0.25\right)^{[25]}$ and $\left[\operatorname{Ln}(\mathrm{L} 10)_{3}\right]^{3+}$ $\left(0.01<A F_{i}<0.33\right) .{ }^{[33]}$ The large $A F_{i}$ values observed for Me18 and Me19 result from minor paramagnetic shifts associated with negligible spin delocalization $\left(F_{i}\right)$ and dipolar effects $\left(S_{i}\right)$.

The $F_{i}$ values are negligible for protons separated from the paramagnetic center by more than five bonds, thus justifying that the contact contribution can be limited to a single magnetic center in $\left[\mathrm{Ln}_{3}(\mathrm{~L} 7)_{3}\right]^{9+}$. Interestingly, the absolute values $\left|F_{i}\right|$ for the central pyridine protons $\mathrm{H} 1$ and $\mathrm{H} 2$ are larger than those found for the related protons of the terminal pyridine groups $\mathrm{H} 9-\mathrm{H} 11$; this strongly suggests larger spin delocalization onto the bis(benzimidazole)pyridine units. These results closely parallel the $\left|F_{i}\right|$ values obtained for $\left[\operatorname{Ln}(\mathrm{L} 9)_{3}\right]^{3+}\left(\left|F_{\mathrm{H} 1}\right|=0.26,\left|F_{\mathrm{H} 2}\right|=0.42\right),{ }^{[25]}$ a model for the central $\mathrm{LnN}_{9}$ metallic site, and which are larger than those found in $\left[\mathrm{Ln}(\mathrm{L} 10)_{3}\right]^{3+}\left(\left|F_{\mathrm{H} 1}\right|=0.11,\left|F_{\mathrm{H} 2}\right|=0.13\right),{ }^{[33]}$ a model for the terminal $\mathrm{LnN}_{6} \mathrm{O}_{3}$ metallic sites The unsymmetrical delocalization $\left|F_{\mathrm{H} 9}\right|>\left|F_{\mathrm{H} 11}\right|$ is characteristic for NNO tridentate binding units, as previously established for heterobimetallic $\mathrm{LnCo}^{\mathrm{III}}$ helicates in which $\mathrm{Ln}^{\mathrm{III}}$ lies in a similar $\mathrm{LnN}_{6} \mathrm{O}_{3}$ site. ${ }^{[36]}$ The structural factor $S_{i}$ is difficult to interpret because it combines two crystal-field and three geometrical parameters. The maximum values found for $\mathrm{H} 5$ and $\mathrm{H} 6$ confirm the tight helical wrapping of the strands that forces them to point inside the triple helix, close to the metal ions (i.e., $\left(r_{\mathrm{i}}^{\mathrm{n}}\right)^{-3}$ are large). The larger values of $S_{i}$ observed for $\mathrm{H} 9-\mathrm{H} 11$ relative to those obtained for the central pyridine $(\mathrm{H} 1, \mathrm{H} 2)$ are responsible for the strong paramagnetic shift experienced by the terminal pyridine ring; however, its eventual assignment to specific geometrical parameters requires the evaluation of the crystal-field parameters. Taking the crystal structure of $\left[\mathrm{Eu}_{3}(\mathrm{~L} 7)_{3}\right]^{9+}$ as a structural model for the solution structure, the geometrical factors $G_{i}^{m}(m=1-3)$ can be calculated (Table S8 in the Supporting Information) and a multilinear least-squares fit of $S_{i}$ versus $G_{i}^{1}$ and $G_{i}^{2}+G_{i}^{3}$ for the eleven aromatic protons $\mathrm{H} 1-\mathrm{H} 11$ gives $B_{0}^{\text {2central }}=-48(3)$ and $B_{0}^{2^{\text {terminal }}}=-70(3) \cdot{ }^{[45]}$ The observation of negative signs for the two crystal-field parameters implies that the axial coordinates $\theta_{i}$ of the donor atoms occupying the vertices of the trigonal prisms in the central $\mathrm{LnN}_{9}$ and in the terminal $\mathrm{LnN}_{6} \mathrm{O}_{3}$ pseudo-tricapped trigonal prismatic sites are comparable and larger than $45^{\circ},{ }^{[3,46]}$ in agreement with average $\theta_{i}=50.8^{\circ}$ (Eu1), $\theta_{i}=50.3^{\circ}(\mathrm{Eu} 2)$, and $\theta_{i}=49.5^{\circ}$ (Eu3) obtained for $\left[\mathrm{Eu}_{3}(\mathrm{~L} 7)_{3}\right]^{9+}$ in the solid state (Tables S5-S7 in the Supporting Information). The quality of the linear correlation is satisfying and leads to an agreement factor $A F_{S}=0.06$ between calculated and experimental $S_{i}$ factors; this strongly suggests that only minor structural changes occur between the solid-state and the solution structures in these rigid polymetallic helicates, as previously established for bimetallic $\mathrm{d}-\mathrm{f}^{[36]}$ and $\mathrm{f}-\mathrm{f}^{[17]}$ helicates. We can now rationalize the origin of the larger values observed for $S_{\mathrm{H} 9-\mathrm{H} 11}$ relative to $S_{\mathrm{H} 1, \mathrm{H} 2}$; these result from a combination of 1 ) the larger crystal-field effects associated with the terminal sites $\left(\left|B_{0}^{2^{\text {terminal }}}\right|>\left|B_{0}^{2^{\text {central }}}\right|\right)$ and 2) the larger compensation effect resulting from opposite paramagnetic contributions in the central metallic site [i.e., $G_{i}^{1}$ and $G_{i}^{2}+G_{i}^{3}$ display opposite signs for all pyridine protons (Table S8 in the Supporting Information), but the absolute value of the ratios $\left|B_{0}^{2^{\text {central }}} G_{i}^{1} / B_{0}^{2^{\text {terminal }}}\left(G_{i}^{2}+G_{i}^{3}\right)\right|=1.7-1.8$ are smaller for $\mathrm{H} 1$ and $\mathrm{H} 2$ than $\left|B_{0}^{\text {2terminal }}\left(G_{i}^{2}+G_{i}^{3}\right) / B_{0}^{2 \text { central }} G_{i}^{1}\right|=$ 5.8-6.9 for H9-H11]. Finally, the only significant discrepancies evidenced between experimental and calculated paramagnetic shifts occur for $\mathrm{H} 1, \mathrm{H} 2, \mathrm{H} 5$, and $\mathrm{H} 6$ in $\left[\mathrm{Eu}_{3}(\mathrm{~L} 7)_{3}\right]^{9+}$ (Table 4), because these protons possess large $F_{i}$ constants (Table 5). The non-magnetic ${ }^{7} \mathrm{~F}_{0}$ ground state of $\mathrm{Eu}^{\mathrm{III}}$ prevents a reliable definition of the Landé factor $(g)$, and we have used the standard spin expectation values $\left\langle S_{z}\right\rangle_{\mathrm{Eu}}=10.68^{[35,39]}$ associated with $g\left({ }^{7} \mathrm{~F}_{0}\right)=5^{[47]}$ for our calculations of $F_{i}$ and $S_{i}$ given in Table 5. However, a systematic survey of paramagnetic data led Pinkerton et al. to propose that the non-magnetic $\mathrm{Eu}^{\mathrm{III}}$ ground-state is better modeled with $g\left({ }^{7} \mathrm{~F}_{0}\right)=4.4$ and $\left\langle S_{z}\right\rangle_{\mathrm{Eu}}=$ 7.5. ${ }^{[48]} \mathrm{Re}$-calculations with Equation (11) and the latter values do not improve the quality of the separation of contact and pseudo-contact shifts for $\left[\operatorname{Ln}_{3}(\mathrm{~L} 7)_{3}\right]^{9+}$, and the resulting values of $F_{i}$ and $S_{i}$ only marginally differ from those reported in Table 5. However, slightly better predictions can be made for $\mathrm{H} 1, \mathrm{H} 2, \mathrm{H} 5$, and $\mathrm{H} 6$ in $\left[\mathrm{Eu}_{3}(\mathrm{~L} 7)_{3}\right]^{9+}$ (Table 4). We conclude from the analysis of NMR data that the triple-stranded helical 
structure is maintained in solution for $\mathrm{Ln}=\mathrm{La}-\mathrm{Lu}$ and that isostructurality characterizes the first part of the lanthanide series $(\mathrm{Ln}=\mathrm{Ce}-\mathrm{Tb})$. The crystal-field parameters obtained in solution are compatible with minor variations between the solid and the solution structures, but abrupt variations of these parameters near the middle of the lanthanide series prevent the analysis of strongly paramagnetic complexes $(\mathrm{Ln}=\mathrm{Dy}-$ $\mathrm{Yb}$ ) with the one-nucleus technique [Eq. (11)].

\section{Multicenter luminescence and photophysical properties of complexes 5-9}

Ligand-centered luminescence: The absorption spectrum of L7 in acetonitrile displays a broad band centered at $30680 \mathrm{~cm}^{-1}\left(\varepsilon=78000 \mathrm{M}^{-1} \mathrm{~cm}^{-1}\right)$ and assigned to the envelope of the $\pi \rightarrow \pi^{*}$ transitions. This band is slightly red-shifted by approximately $300 \mathrm{~cm}^{-1}$ upon complexation to $\mathrm{Ln}^{\mathrm{III}}$ in 5-9 (Figure 1a), and a broad shoulder appears on the low-energy side $\left(25600 \mathrm{~cm}^{-1}\right)$, a phenomenon also seen in the reflectance spectra of solid-state samples for which the shoulder becomes the most intense peak of the spectra (Table 6). Excitation through the ligand-centered $\pi \rightarrow \pi^{*}$ transitions in L7 (solid state, $77 \mathrm{~K}, \lambda_{\text {exc }}=30674 \mathrm{~cm}^{-1}$ ) produces strong and poorly resolved fluorescence at $24970 \mathrm{~cm}^{-1}$ (0-0 phonon), originating from the ${ }^{1} \pi \pi^{*}$ level, together with a weak structured phosphorescence at $19920 \mathrm{~cm}^{-1}(0-0$ phonon, vibronic progression $\approx 1200 \mathrm{~cm}^{-1}$ ), associated with ${ }^{3} \pi \pi^{*}$ emission (biexponential decay: $\tau=234(5)$ and $16(1) \mathrm{ms}$ at $77 \mathrm{~K})$. Very similar emission characteristics are obtained for the diamagnetic complexes with $\mathrm{La} \mathrm{(5)}$ and $\mathrm{Lu}(\mathbf{9})$, except for a 1500 $2200 \mathrm{~cm}^{-1}$ red-shift of the ${ }^{1} \pi \pi^{*}$ levels associated with the complexation of the ligand strands (Table 6). For the paramagnetic Gd complex 7, the metal-centered excited levels are lying at too high energy to be accessible for intramolecular energy transfers from the ${ }^{1} \pi \pi^{*}$ or ${ }^{3} \pi \pi^{*}$ levels, ${ }^{[49]}$ but the Coulomb interactions between the electrons of the ligands and the metal ions mix the ligand-centered triplet and singlet wavefunctions. ${ }^{[50]}$ Consequently, the oscillator strength of the spin-forbidden emission of the ${ }^{3} \pi \pi^{*}$ level increases, the associated characteristic lifetime $\tau\left({ }^{3} \pi \pi^{*}\right)$ drops by two orders of magnitude (Table 6), and ${ }^{1} \pi \pi^{*} \rightarrow{ }^{3} \pi \pi^{*}$ intersystem crossing becomes more efficient. ${ }^{[50]}$ The emission spectrum of $\mathbf{7}$ at $77 \mathrm{~K}$ thus displays a weak ${ }^{1} \pi \pi^{*}$ fluorescence at $23030 \mathrm{~cm}^{-1}$ dominated by a strong ${ }^{3} \pi \pi^{*}$ emission at $20260 \mathrm{~cm}^{-1}(0-0$ phonon, vibronic progression $\approx 1200 \mathrm{~cm}^{-1}$, Figure $\mathrm{S} 4$ in the Supporting Information). It should be noticed that the heavy atom effect (i.e., spin-orbit mixing) similarly affects the intersystem crossing and phosphorescence processes in the three trimetallic helicates with $\mathrm{La} \mathrm{(5),} \mathrm{Gd} \mathrm{(7),} \mathrm{and} \mathrm{Lu}(\mathbf{9})$, but the electronic interaction matrix responsible for the large increase of the ${ }^{3} \pi \pi^{*}$ emission in $\mathbf{7}$ exists only for paramagnetic ions.

Multi-metal-centered luminescence: The ligand-centered luminescence in $\left[\mathrm{Eu}_{3}(\mathrm{~L} 7)_{3}\right]\left(\mathrm{CF}_{3} \mathrm{SO}_{3}\right)_{9} \cdot\left(\mathrm{H}_{2} \mathrm{O}\right)_{4}(6)$ is quenched by efficient $\mathrm{L} 7 \rightarrow \mathrm{Eu}^{\mathrm{III}}$ energy-transfer processes, and excitation through the $\pi \rightarrow \pi^{*}$ transitions produces only the Eucentered red luminescence, characterized by sharp bands associated with ${ }^{5} \mathrm{D}_{0} \rightarrow{ }^{7} \mathrm{~F}_{j}(j=0-6)$ transitions (Figure 8, relative corrected and integrated intensities are collected in
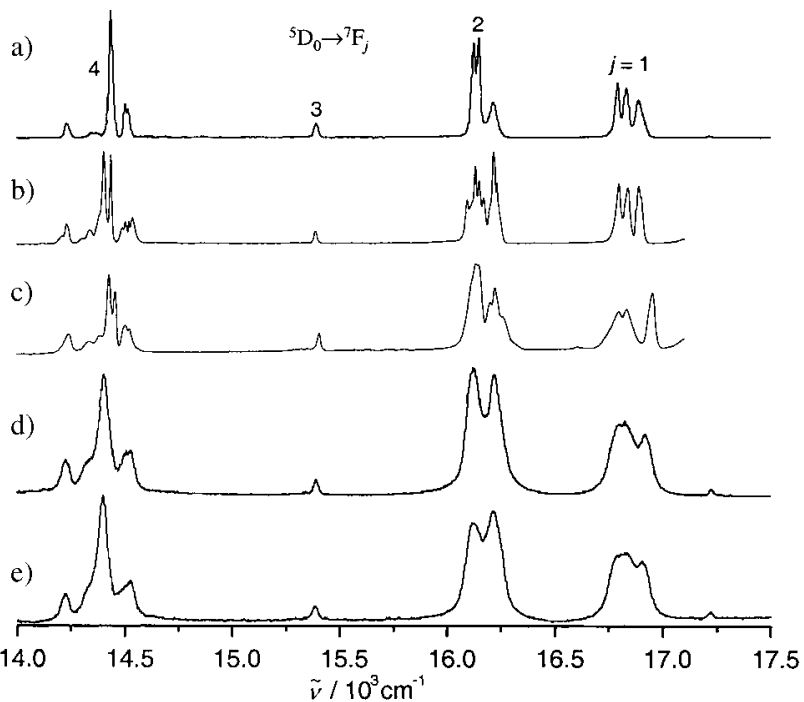

Figure 8. Emission spectra of $\left[\mathrm{Eu}_{3}(\mathrm{~L} 7)_{3}\right]\left(\mathrm{CF}_{3} \mathrm{SO}_{3}\right)_{9}\left(\mathrm{H}_{2} \mathrm{O}\right)_{4}$ recorded under various conditions: a) solid state, $10 \mathrm{~K}$, excitation via the ligand-centered ${ }^{1} \pi \pi^{*}$ levels $\left.\left(\tilde{v}_{\mathrm{ex}}=24016 \mathrm{~cm}^{-1}\right), \mathrm{b}\right)$ solid state, $10 \mathrm{~K}$, selective excitation of site I $\left.\left(\tilde{v}_{\text {ex }}=17211 \mathrm{~cm}^{-1}\right), \mathrm{c}\right)$ solid state, $10 \mathrm{~K}$, selective excitation of site II $\left(\tilde{v}_{\mathrm{ex}}=17238 \mathrm{~cm}^{-1}\right)$, d) solid state, $295 \mathrm{~K}$, excitation via the ligand-centered ${ }^{1} \pi \pi^{*}$ levels $\left(\tilde{v}_{\mathrm{ex}}=27778 \mathrm{~cm}^{-1}\right)$, and e) solution (acetonitrile $\left.10^{-3} \mathrm{M}\right), 295 \mathrm{~K}$, excitation via the ligand-centered ${ }^{1} \pi \pi^{*}$ levels $\left(\tilde{v}_{\mathrm{ex}}=27397 \mathrm{~cm}^{-1}\right)$.

Table S9 in the Supporting Information). Emission spectra in the solid state show a very weak, broad, and slightly asymmetric ${ }^{5} \mathrm{D}_{0} \rightarrow{ }^{7} \mathrm{~F}_{0}$ transition $\left(10 \mathrm{~K}, 17219 \mathrm{~cm}^{-1}\right.$, fwhh $=$ $24.3 \mathrm{~cm}^{-1} ; 295 \mathrm{~K}, 17225 \mathrm{~cm}^{-1}$, fwhh $=27.4 \mathrm{~cm}^{-1}$ ) compatible with the luminescence emitted by a single metal ion center, termed site I. ${ }^{[51]}$ At $10 \mathrm{~K}$, the crystal field splitting of site I can be interpreted in terms of a pseudo- $D_{3}$ symmetry around the

Table 6. Ligand-centered absorption at $295 \mathrm{~K}$ and emission properties at $77 \mathrm{~K}$ for the ligand $\mathrm{L7}$ and its complexes $\left[\mathrm{Ln}_{3}(\mathrm{~L})_{3}\right]\left(\mathrm{CF}_{3} \mathrm{SO}\right)_{9} \cdot x \mathrm{H}_{2} \mathrm{O}\left(\mathrm{Ln}=\mathrm{La}_{\text {, }}\right.$ $x=4(5) ; \mathrm{Ln}=\mathrm{Eu}, x=4(\mathbf{6}) ; \mathrm{Ln}=\mathrm{Gd}, x=2(7) ; \mathrm{Ln}=\mathrm{Tb}, x=12(8) ; \mathrm{Ln}=\mathrm{Lu}, x=6(9))$ in the solid state.

\begin{tabular}{|c|c|c|c|c|c|c|c|c|c|}
\hline \multirow[b]{2}{*}{ L7 } & \multicolumn{2}{|c|}{$E\left(\pi \rightarrow \pi^{*}\right)\left[\mathrm{cm}^{-1}\right]^{[\mathrm{a}]}$} & \multirow{2}{*}{$\begin{array}{l}E\left(\pi \rightarrow \pi^{*}\right)\left[\mathrm{cm}^{-1}\right]^{[\mathrm{b}]} \\
28490\end{array}$} & \multirow{2}{*}{$\begin{array}{l}E\left({ }^{1} \pi \pi^{*}\right)\left[\mathrm{cm}^{-1}\right]^{[\mathrm{c}]} \\
24970\end{array}$} & \multicolumn{2}{|c|}{$E\left({ }^{3} \pi \pi^{*}\right)\left[\mathrm{cm}^{-1}\right]^{[\mathrm{c}]}$} & \multicolumn{3}{|c|}{$\tau\left({ }^{3} \pi \pi^{*}\right)[\mathrm{ms}]$} \\
\hline & 30680 & & & & $19920 \mathrm{sh}$ & 18770 & & $234(5)$ & $16(1)$ \\
\hline$\left[\mathrm{La}_{3}(\mathrm{~L} 7)_{3}\right]^{9+}$ & 30320 & $25870(\mathrm{sh})$ & 25125 & 22780 & 20040 & 18760 & 17450 & 154(3) & $23(2)$ \\
\hline$\left[\mathrm{Eu}_{3}(\mathrm{~L} 7)_{3}\right]^{9+}$ & 30390 & $25770(\mathrm{sh})$ & 24940 & [d] & [d] & & & & \\
\hline$\left[\mathrm{Gd}_{3}(\mathrm{~L} 7)_{3}\right]^{9+}$ & 30120 & $25640(\mathrm{sh})$ & 24940 & 23030 & 20260 & 18940 & 17690 & $1.07(1)$ & $0.22(2)$ \\
\hline$\left[\mathrm{Tb}_{3}(\mathrm{~L} 7)_{3}\right]^{9+}$ & 30080 & $25640(\mathrm{sh})$ & 25000 & [d] & [d] & & & & \\
\hline$\left[\mathrm{Lu}_{3}(\mathrm{~L} 7)_{3}\right]^{9+}$ & 29900 & $25380(\mathrm{sh})$ & 24875 & 23420 & 20030 & 18800 & 17570 & $98(1)$ & $14.5(1)$ \\
\hline
\end{tabular}

[a] $10^{-3} \mathrm{M}$ in acetonitrile, $\mathrm{sh}=$ soulder. [b] Reflectance spectra in the solid state. [c] Data obtained from the emission spectra. [d] ${ }^{1} \pi \pi^{*}$ and ${ }^{3} \pi \pi^{*}$ luminescence quenched by transfer to $\mathrm{Ln}^{\mathrm{III}}$ ion. 
$\mathrm{Eu}^{\mathrm{III}}$ ion (Table 7). The faint ${ }^{5} \mathrm{D}_{0} \rightarrow{ }^{7} \mathrm{~F}_{0}$ transition (1\% of the intensity of the magnetic dipole ${ }^{5} \mathrm{D}_{0} \rightarrow{ }^{7} \mathrm{~F}_{1}$ transition) is consistent with the fact that it is symmetry forbidden in the $D_{3}$ point group. ${ }^{[51]}$ The three observed transitions to the ${ }^{7} \mathrm{~F}_{1}$ level

Table 7. Energy $\left[\mathrm{cm}^{-1}\right]$ of the identified crystal-field sub-levels of the $\mathrm{Eu}\left({ }^{7} \mathrm{~F}_{j}\right)$ manifold $(j=1-4)$ in $\left[\mathrm{Eu}_{3}(\mathrm{~L} 7)_{3}\right]\left(\mathrm{CF}_{3} \mathrm{SO}_{3}\right)_{9} \cdot\left(\mathrm{H}_{2} \mathrm{O}\right)_{4}(\mathbf{6})$ as determined from excitation and emission spectra in the solid state at 10 and $295 \mathrm{~K}\left({ }^{7} \mathrm{~F}_{0}\right.$ is taken as the origin).

\begin{tabular}{|c|c|c|c|c|}
\hline \multirow{3}{*}{$\tilde{v}_{\text {exo }}\left[\mathrm{cm}^{-1}\right]$} & \multicolumn{2}{|c|}{$10 \mathrm{~K}$} & \multicolumn{2}{|c|}{$295 \mathrm{~K}$} \\
\hline & 24016 & 17238 & 27778 & 17239 \\
\hline & Site I & Site II & Site I & Site II \\
\hline${ }^{7} F_{0}$ & 0 & 0 & 0 & 0 \\
\hline \multirow[t]{3}{*}{${ }^{7} \mathrm{~F}_{1}$} & 327 & 295 & 310 & 304 \\
\hline & 381 & 410 & 394 & 408 \\
\hline & 423 & 448 & 427 & 446 \\
\hline \multirow[t]{5}{*}{${ }^{7} \mathrm{~F}_{2}$} & 997 & 981 & 1003 & 986 \\
\hline & 1065 & 1019 & 1100 & 1024 \\
\hline & 1085 & 1046 & & 1120 \\
\hline & & 1103 & & \\
\hline & & 1122 & & \\
\hline${ }^{7} F_{3}$ & 1824 & 1837 & 1838 & 1848 \\
\hline \multirow[t]{6}{*}{${ }^{7} \mathrm{~F}_{4}$} & 2691 & 2715 & 2700 & 2715 \\
\hline & 2710 & 2736 & 2723 & 2735 \\
\hline & 2773 & 2782 & 2822 & 2830 \\
\hline & 2843 & 2811 & 2898 & 2912 \\
\hline & 2863 & 2854 & 2996 & 3010 \\
\hline & 2978 & 2997 & 3093 & 3106 \\
\hline${ }^{5} \mathrm{D}_{0}$ & 17219 & 17238 & 17225 & 17239 \\
\hline
\end{tabular}

can be labeled $A_{1} \rightarrow A_{2}\left(A_{2}\right.$ at $327 \mathrm{~cm}^{-1}$ with respect to $\left.{ }^{7} F_{0}\right)$ and $\mathrm{A}_{1} \rightarrow$ split $\mathrm{E}$ sublevel (barycenter: $402 \mathrm{~cm}^{-1}$ ). The splitting of the $\mathrm{E}$ sublevel is connected to the distortion from the idealized $D_{3}$ symmetry and amounts to $\Delta E_{\mathrm{E}-\mathrm{E}}=42 \mathrm{~cm}^{-1}$. A theoretical approach from the point-charge electrostatic model (PCEM) allows approximate correlations between the magnitude and signs of the second-rank crystal-field parameters $B_{0}^{2}$ and $B_{2}^{2}$ and the energy of the $A$ and $E$ levels in distorted trigonal tricapped prismatic sites. ${ }^{[3,46]}$ Firstly, $B_{0}^{2}$ of site $I$ is negative because $A_{2}$ lies at lower energy than the twofold degenerate sublevel E. ${ }^{[3]}$ Moreover, the absolute magnitude of $B_{0}^{2}$ is proportional to the difference in energy between the ${ }^{7} \mathrm{~F}_{1}\left(\mathrm{~A}_{2}\right)$ and ${ }^{7} \mathrm{~F}_{1}(\mathrm{E})$ sublevels $\left(\Delta E_{\mathrm{A}-\mathrm{E}}\right)$, which increases in the order $\left[\mathrm{Eu}(\mathrm{L} 10)_{3}\right]^{3+}\left(53 \mathrm{~cm}^{-1}\right)^{[33]}<$ site I in $\left[\mathrm{Eu}_{3}(\mathrm{~L} 7)_{3}\right]^{9+}\left(75 \mathrm{~cm}^{-1}\right)<\left[\mathrm{LaEu}(\mathrm{L} 5)_{3}\right]^{6+} \quad\left(104 \mathrm{~cm}^{-1}\right)^{[19]}<$ $\left[\mathrm{Eu}(\mathrm{L} 9)_{3}\right]^{3+} \quad\left(114 \mathrm{~cm}^{-1}\right)^{[32]}<$ anhydrous $\quad\left[\mathrm{Eu}_{2}(\mathrm{~L} 1)_{3}\right]^{6+}$ $\left(127 \mathrm{~cm}^{-1}\right){ }^{[13]}$ Secondly, the magnitude of $B_{2}^{2}$ is proportional to the difference in energy between the split components of the ${ }^{7} \mathrm{~F}_{1}(\mathrm{E})$ sublevel. ${ }^{[3,46]}$ Examination of the reported splittings $\Delta E_{\mathrm{E}-\mathrm{E}}$ for $\left[\mathrm{Eu}(\mathrm{L} 9)_{3}\right]^{3+}\left(17 \mathrm{~cm}^{-1}\right),{ }^{[32]}$ anhydrous $\left[\mathrm{Eu}_{2}(\mathrm{~L} 1)_{3}\right]^{6+}$ $\left(18 \mathrm{~cm}^{-1}\right),{ }^{[13]}\left[\mathrm{LaEu}(\mathrm{L} 5)_{3}\right]^{6+}\left(46 \mathrm{~cm}^{-1}\right),{ }^{[19]}$ and $\left[\mathrm{Eu}(\mathrm{L} 10)_{3}\right]^{3+}$ $\left(57 \mathrm{~cm}^{-1}\right)^{[33]}$ points to a relatively large distortion around the $\mathrm{Eu}^{\mathrm{III}}$ ions for site I $\left(\Delta E_{\mathrm{E}-\mathrm{E}}=42 \mathrm{~cm}^{-1}\right)$ in the trimetallic helicate. The ${ }^{5} \mathrm{D}_{0} \rightarrow{ }^{7} \mathrm{~F}_{2}$ transition displays two main bands assigned to the allowed electric dipole transitions $\mathrm{A}_{1} \rightarrow \mathrm{E}$ in $D_{3}$ symmetry, the latter being further split into two components separated by $20 \mathrm{~cm}^{-1}$. The analysis of the ${ }^{5} \mathrm{D}_{0} \rightarrow{ }^{7} \mathrm{~F}_{4}$ transition shows six components, also consistent with a distorted trigonal symmetry. ${ }^{[22,51]}$ All these data are compatible with site I being composed of a set of very similar slightly distorted pseudo-trigonal Eu ${ }^{\mathrm{III}}$ sites associated with a microcrystalline sample containing some minor structural defects.

However, the crystal structure of $\left[\mathrm{Eu}_{3}(\mathrm{~L} 7)_{3}\right]^{9+}$ involves two different pseudo-tricapped trigonal prismatic sites: a central $\mathrm{EuN}_{9}$ and two terminal $\mathrm{EuN}_{6} \mathrm{O}_{3}$ sites; these are expected to produce specific metal-centered emission in a 1:2 ratio. The observation of single site upon ligand irradiation in $\left[\mathrm{Eu}_{3}-\right.$ $\left.(\mathrm{L} 7)_{3}\right]^{9+}$ results from the quantum yield associated with the central $\mathrm{EuN}_{9}$ site; this is expected to be orders of magnitude smaller than that of $\mathrm{EuN}_{6} \mathrm{O}_{3}$, because low-lying LMCT states quench the ${ }^{3} \pi \pi^{*}$ energy transfer. ${ }^{[52]}$ The 50 -fold increase in the quantum yield observed when going from $\left[\mathrm{Eu}_{2}(\mathrm{~L} 1)_{3}\right]^{6+}$ (which contains two $\mathrm{EuN}_{9}$ sites) $)^{[13]}$ to $\left[\mathrm{Eu}_{2}(\mathrm{~L} 2)_{3}\right]^{6+}$ (which contains two $\mathrm{EuN}_{6} \mathrm{O}_{3}$ sites $)^{[14]}$ strongly supports this hypothesis, and we have resorted to high-resolution laser-excitation spectra of the ${ }^{5} \mathrm{D}_{0} \leftarrow{ }^{7} \mathrm{~F}_{0}$ transition for evidencing the existence of a second site. Figure 9 shows the excitation profiles obtained for $\mathbf{6}$ at

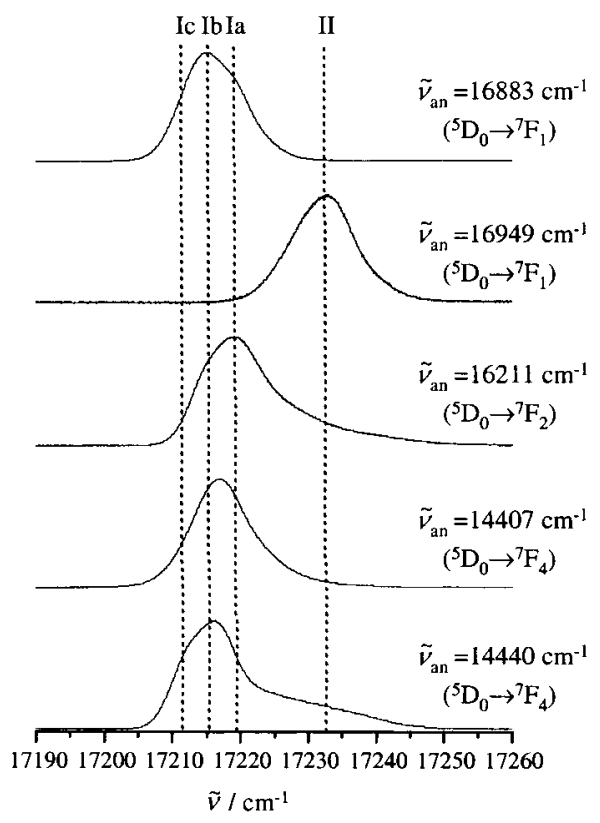

Figure 9. Excitation profile of the ${ }^{5} \mathrm{D}_{0} \leftarrow{ }^{7} \mathrm{~F}_{0}$ transition for $\left[\mathrm{Eu}_{3^{-}}\right.$ $\left.(\mathrm{L} 7)_{3}\right]\left(\mathrm{CF}_{3} \mathrm{SO}_{3}\right)_{9} \cdot\left(\mathrm{H}_{2} \mathrm{O}\right)_{4}(6)$ at $10 \mathrm{~K}$ upon monitoring various $\mathrm{Eu}\left({ }^{5} \mathrm{D}_{0} \rightarrow\right.$ ${ }^{7} \mathrm{~F}_{j}$ ) transitions.

$10 \mathrm{~K}$ upon monitoring different $\mathrm{Eu}\left({ }^{5} \mathrm{D}_{0} \rightarrow{ }^{7} \mathrm{~F}_{j}\right)(j=1,2,4)$ transitions (Table S10 in the Supporting Information). The three closely spaced sites Ia, Ib, and Ic $\left(17210-17220 \mathrm{~cm}^{-1}\right.$, Figure S5 in the Supporting Information) correspond to a single site affected by small defects in the microcrystalline sample, while site II $\left(17238 \mathrm{~cm}^{-1}\right)$ unambiguously corresponds to a different environment. Selective excitation of sites Ia, Ib, and Ic produces similar intense emission spectra (Figure $8 \mathrm{~b}$ ) reminiscent of that obtained upon irradiation of the ligandcentered ${ }^{1} \pi \pi^{*}$ state (Figure $8 \mathrm{a}$ ) and assigned to the terminal $\mathrm{EuN}_{6} \mathrm{O}_{3}$ sites (site I). Selective excitation of site II provides a weak emission spectrum with a splitting pattern of the ${ }^{7} \mathrm{~F}_{j}$ manifolds typical of distorted $D_{3}$ symmetry (Figure 8c). Detailed analysis of the ${ }^{5} \mathrm{D}_{0} \rightarrow{ }^{7} \mathrm{~F}_{1}$ transition at $10 \mathrm{~K}$ leads to the two magnetic dipole allowed components $A_{1} \rightarrow A_{2}\left(A_{2}\right.$ at 
$295 \mathrm{~cm}^{-1}$ with respect to ${ }^{7} \mathrm{~F}_{0}$ ) and $\mathrm{A}_{1} \rightarrow \mathrm{E}$ level (barycenter: $429 \mathrm{~cm}^{-1}$ ), the latter being split by $\Delta E_{\mathrm{E}-\mathrm{E}}=38 \mathrm{~cm}^{-1}$ (Table 7). The value of $B_{0}^{2}$ is still negative for site $\mathrm{II},{ }^{[3,46]}$ but the separation between the $\mathrm{A}_{2}$ and $\mathrm{E}$ (barycenter) sublevels $\left(\Delta E_{\mathrm{A}-\mathrm{E}}=134 \mathrm{~cm}^{-1}\right)$ is significantly larger than that observed for site I $\left(75 \mathrm{~cm}^{-1}\right)$; this implies a larger $B_{0}^{2}$ parameter for site II. Although the nephelauxetic effects produced by the $\mathrm{EuN}_{9}$ and $\mathrm{EuN}_{6} \mathrm{O}_{3}$ environments are very similar ${ }^{[22,33,53]}$ and cannot be used for unambiguously assigning site I and site II (we calculate energies of 17236 and $17233 \mathrm{~cm}^{-1}$ for the ${ }^{7} \mathrm{~F}_{0} \rightarrow$ ${ }^{5} \mathrm{D}_{0}$ transitions of $\mathrm{EuN}_{9}$ and $\mathrm{EuN}_{6} \mathrm{O}_{3}$, respectively, at $295 \mathrm{~K}),{ }^{[22,33]}$ the faint emission intensity of site II matches the one previously reported for $\left[\mathrm{Eu}(\mathrm{L} 9)_{3}\right]^{3+} ; ;^{[32]}$ hence, we can safely ascribe it to the central $\mathrm{EuN}_{9}$ site. The negative signs of $B_{0}^{2^{\text {central }}}$ and $B_{0}^{2^{\text {terminal }}}$ agree with axial coordinates $\theta_{i}$ for the donor atoms that occupy the vertices of the trigonal prisms larger than $45^{\circ}$ (Tables S5-S7 in the Supporting Information), ${ }^{[3,46]}$ but the order $\left|B_{0}^{2^{\text {central }}}\right|>\left|B_{0}^{2^{\text {terminal }}}\right|$ found by luminescence for $\left[\mathrm{Eu}_{3}(\mathrm{~L} 7)_{3}\right]^{9+}$ in the solid state contrasts with $\left|B_{0}^{2^{\text {central }}}\right|<\mid$ $B_{0}^{2^{\text {terminal }}} \mid$ observed by paramagnetic NMR for $\left[\mathrm{Ln}_{3}(\mathrm{~L} 7)_{3}\right]^{9+}$ $(\mathrm{Ln}=\mathrm{Ce}-\mathrm{Tb})$ in acetonitrile. Although broadened in solution, the $\operatorname{Eu}\left({ }^{5} \mathrm{D}_{0} \rightarrow{ }^{7} \mathrm{~F}_{j}\right)$ transitions originating from site I can be observed for $\left[\mathrm{Eu}_{3}(\mathrm{~L} 7)_{3}\right]^{9+}$ in acetonitrile at $295 \mathrm{~K}$ upon excitation of the ligand-centered ${ }^{1} \pi \pi^{*}$ levels (Figure $8 \mathrm{e}$ ). The similarity between the solid-state (Figure 8d) and solution (Figure 8e) spectra points to similar crystal-field parameters for the terminal rigid $\mathrm{EuN}_{6} \mathrm{O}_{3}$ sites. Although the emission originating from the central $\mathrm{EuN}_{9}$ is too weak to be detected in solution, the invariance of $B_{0}^{\text {terminal }}$ between solid-state and solution samples suggests that the inversion of the relative magnitude of the second-rank crystal-field parameter observed by NMR spectroscopy $\left(\left|B_{0}^{2^{\text {central }}}\right|<\left|B_{0}^{2^{\text {terminal }}}\right|\right)$ may result from some geometrical relaxation of the flexible central site that reduces $\left|B_{0}^{2^{\text {central }}}\right|$. Indeed, it has to be stressed here that 1 ) a slight increase of the $\mathrm{Eu}-\mathrm{N}$ distances, which corresponds to a minor elongation of the trigonal prismatic environment, may dramatically affect $B_{0}^{2}$, as do minor distortions from the idealized geometry; ${ }^{[38 c]} 2$ ) the approximate estimation of $B_{0}^{2}$ and $B_{2}^{2}$ from the splitting pattern of the $\operatorname{Eu}\left({ }^{7} \mathrm{~F}_{1}\right)$ level is restricted to minor distortions from trigonal symmetry; ${ }^{[3,46]}$ and 3 ) possible rhombic anisotropy for trigonal complexes in solution is neglected in the approach proposed by Bleaney [Eq. (8)]. ${ }^{[38]}$ The absolute quantum yield of $\left[\mathrm{Eu}_{3}(\mathrm{~L} 7)_{3}\right]^{9+}$ in acetonitrile at $295 \mathrm{~K}$ is small $\left(\Phi=1.1 \times 10^{-4}\right)$ and it reflects exclusively the emission of the two terminal metallic sites; this can be compared with $\Phi=3.5 \times 10^{-3}$ reported for $\left[\mathrm{Eu}_{2}(\mathrm{~L} 2)_{3}\right]^{6+}$ under the same conditions. ${ }^{[14]}$ The 30 -fold decrease of the quantum yield in the trimetallic helicate can be tentatively assigned to intramolecular quenching effect provided by the LMCT states located on the neighboring EuN $_{9}$ unit. ${ }^{[52]}$

The $\mathrm{Eu}\left({ }^{5} \mathrm{D}_{0}\right)$ luminescence decays of the terminal $\mathrm{EuN}_{6} \mathrm{O}_{3}$ (site I) and central $\mathrm{EuN}_{9}$ (site II) metallic sites are single exponentials, and their lifetimes are independent of the excitation and analyzing wavelengths (Table S11 in the Supporting Information). In the $10-100 \mathrm{~K}$ range, the lifetimes of both sites are rather large and similar $(\tau($ site $\mathrm{I})=$ $2.3(1) \mathrm{ms}$ and $\tau($ site $\mathrm{II})=2.2(1) \mathrm{ms}$ ) ; this points to fairly rigid coordination spheres and no solvent molecule interacting with the metal ions, in agreement with 1 ) the crystal structure of $\mathbf{1 0}$ and 2) related lifetimes obtained for nine-coordinate $\mathrm{Eu}^{\mathrm{III}}$ sites in the bimetallic helicates $\left[\mathrm{Eu}_{2}(\mathrm{~L} 1)_{3}\right]^{6+}(1.78(8) \mathrm{ms}$ at $4 \mathrm{~K})^{[13]}$ and $\left[\mathrm{Eu}_{2}(\mathrm{~L} 2)_{3}\right]^{6+}(2.28(2) \mathrm{ms}$ at $10 \mathrm{~K}) \cdot{ }^{[14]}$ Above $200 \mathrm{~K}$, the lifetimes of both sites in $\left[\mathrm{Eu}_{3}(\mathrm{~L} 7)_{3}\right]^{9+}$ sharply decrease to reach $1.7(1) \mathrm{ms}$ at $295 \mathrm{~K}$, because of thermally activated vibrational-quenching processes. Interestingly, the lifetime of the central $\mathrm{EuN}_{9}$ sites is less affected at $295 \mathrm{~K}$ than that reported for the bimetallic model complex $\left[\mathrm{Eu}_{2}(\mathrm{~L} 1)_{3}\right]^{6+}(\tau=$ $0.29(1) \mathrm{ms}$ at $295 \mathrm{~K}) ;^{[13]}$ this suggests that the slide of the strands around the central $\mathrm{EuN}_{9}$ site shifts the LMCT state toward slightly higher energies. In solution, the $\operatorname{Eu}\left({ }^{5} \mathrm{D}_{0}\right)$ lifetime only reflects the emission of the terminal $\mathrm{EuN}_{6} \mathrm{O}_{3}$ sites $(\tau \approx 2.4 \mathrm{~ms}$, Table S11 in the Supporting Information) and compares well with lifetimes measured in the solid state, eventually confirming the lack of interaction between the solvent and the $\mathrm{Eu}^{\mathrm{III}}$ sites.

Finally, efficient sensitization of $\mathrm{Tb}^{\mathrm{III}}$ in $\mathbf{8}$ only occurs at low temperature in the solid state, because thermally activated ${ }^{3} \pi \pi^{*} \leftarrow \mathrm{Tb}\left({ }^{5} \mathrm{D}_{4}\right)$ energy back-transfer processes quench the luminescence at room temperature. ${ }^{[13-15]}$ The emission spectrum is dominated by the ${ }^{5} \mathrm{D}_{4} \rightarrow{ }^{7} \mathrm{~F}_{5}$ transition (Figure $\mathrm{S} 6$ in the Supporting Information), while the $\mathrm{Tb}\left({ }^{5} \mathrm{D}_{4}\right)$ lifetime drops from $2.23-2.30 \mathrm{~ms}$ at $10 \mathrm{~K}$ to $40-96 \mu$ at $295 \mathrm{~K}$ (Table S12 in the Supporting Information). Residual emission originating from the ligand-centered ${ }^{3} \pi \pi^{*}$ state $\left(20000 \mathrm{~cm}^{-1}\right)$ is detected at $295 \mathrm{~K}$ in agreement with the existence of a ${ }^{3} \pi \pi^{*} \leftarrow \mathrm{Tb}\left({ }^{5} \mathrm{D}_{4}\right)$ energy back transfer that depopulates $\mathrm{Tb}\left({ }^{5} \mathrm{D}_{4}\right)$.

\section{Conclusion}

Although the concept of positive cooperativity has been demonstrated in the early 1990's for trimetallic d-block helicates, ${ }^{[27,28,54]}$ its planned application for the stabilization of highly charged polymetallic helicates remains scarce. ${ }^{[1 b, 34,55]}$ In this context, the formation of the triplestranded trimetallic helicates $\left[\mathrm{Ln}_{3}(\mathrm{~L} 7)_{3}\right]^{9+}$ represents the first well-characterized self-assembly process in which the fixation of three 4 f-block ions is driven by positive cooperativity. The considerable electrostatic repulsion associated with the fixation of the third $\mathrm{Ln}^{\mathrm{III}}$ ion is overcome by the preorganization of the receptor, a phenomenon that has deep roots in biological processes for which the overall free energy gains result from multisite interactions (protein zipper, recombination of DNA). ${ }^{[5]}$ The crystal structure and the photophysical properties of $\left[\mathrm{Eu}_{3}(\mathrm{~L} 7)_{3}\right]^{9+}$ evidence the formation of a "regular" triple helix in the solid state, roughly corresponding to the packing of three monometallic triple-helical lanthanide complexes along the threefold axis. The nonequivalence of the terminal $\left(\mathrm{EuN}_{6} \mathrm{O}_{3}\right)$ and central $\left(\mathrm{EuN}_{9}\right)$ metallic sites is clearly evidenced by high-resolution luminescence data and could be useful in the programming of directional intramolecular energy transfers required in the rational design of multicenter luminescent probes. ${ }^{[18,57]}$ Moreover, the significant difference between the crystal-field parameters of the two lanthanide sites in $\left[\mathrm{Ln}_{3}(\mathrm{~L} 7)_{3}\right]^{9+}$ induces large, variable, and tunable paramagnetic anisotropies along the strand, a crucial point for 1) the preparation of magnetically-addressable liquid crystals, ${ }^{[8]} 2$ ) the orientation of biological materials 
in paramagnetic matrices for structural investigation by multidimensional NMR spectroscopy, ${ }^{[58]}$ and 3) the elucidation of the abrupt change affecting the crystal-field parameters near the middle of the lanthanide series (i.e., the "gadolinium break" effect). ${ }^{[41,59]}$ Finally, our paramagnetic NMR study of $\left[\mathrm{Ln}_{3}(\mathrm{~L} 7)_{3}\right]^{9+}(\mathrm{Ln}=\mathrm{Ce}-\mathrm{Tb})$ combined with luminescence data indicate that the triple-helical structure is essentially maintained in solution and that the terminal $\mathrm{EuN}_{6} \mathrm{O}_{3}$ sites do not evidence significant distortions. However, the decrease of the crystal field parameter of the central coordination unit $\operatorname{LnN}_{9}\left(\left|B_{0}^{\text {2entral }}\right|\right)$ in solution with respect to its solid-state value implies that some geometrical relaxation of the central $\mathrm{EuN}_{9}$ site takes place, and this has considerable effects on the magnetic anisotropy.

\section{Experimental Section}

Solvents and starting materials: These were purchased from Fluka AG (Buchs, Switzerland) and used without further purification unless otherwise stated. Thionyl chloride was distilled from elemental sulfur, acetonitrile, dichloromethane, and triethylamine were distilled from $\mathrm{CaH}_{2}$. Silicagel (Acros, $0.035-0.07 \mathrm{~mm}$ ) was used for preparative column chromatography. 3,3'-Dinitro-4,4'-bis( $N$-ethylamino $)$ diphenylmethane $(\mathbf{1})^{[22]}$ and 6- $(N, N$-diethylcarbamoyl)pyridine-2-carboxylic acid (2) ${ }^{[15]}$ were prepared according to literature procedures. The triflate salts $\mathrm{Ln}\left(\mathrm{CF}_{3} \mathrm{SO}_{3}\right)_{3} \cdot x \mathrm{H}_{2} \mathrm{O}(\mathrm{Ln}=\mathrm{La}-$ $\mathrm{Lu}$ ) were prepared from the corresponding oxides (Rhodia, $99.99 \%$ ). The Ln content of solid salts was determined by complexometric titrations with Titriplex III (Merck) in the presence of urotropine and xylene orange. ${ }^{[60]}$

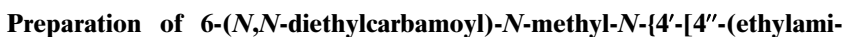
no)-3"'-nitrobenzyl]-2'-nitrophenyl\}pyridine-2-carboxamide (3): A mixture of compound $2(814 \mathrm{mg}, 3.66 \mathrm{mmol})$, thionyl chloride $(2.50 \mathrm{~mL}$, $33.3 \mathrm{mmol})$, and DMF $(0.2 \mathrm{~mL})$ was refluxed for $90 \mathrm{~min}$ in dry dichloromethane $(40 \mathrm{~mL})$. The mixture was evaporated and dried under vacuum. The solid residue was dissolved in dichloromethane $(40 \mathrm{~mL})$ and added dropwise to a solution of $\mathbf{1}(1.147 \mathrm{~g}, 3.33 \mathrm{mmol})$ and triethylamine $(1.4 \mathrm{~mL}$, $9.3 \mathrm{mmol})$ in dichloromethane $(40 \mathrm{~mL})$. The solution was refluxed for $12 \mathrm{~h}$ under an inert atmosphere and evaporated. The residue was partitioned between dichloromethane $(150 \mathrm{~mL})$ and half-saturated aqueous $\mathrm{NH}_{4} \mathrm{Cl}$ solution $(150 \mathrm{~mL})$. The aqueous phase was extracted with dichloromethane $(2 \times 150 \mathrm{~mL})$, and the combined organic phases were dried $\left(\mathrm{Na}_{2} \mathrm{SO}_{4}\right)$ and evaporated. The crude product was purified by column chromatography (silicagel, $\mathrm{CH}_{2} \mathrm{Cl}_{2} /$ hexane $80: 20 \rightarrow \mathrm{CH}_{2} \mathrm{Cl}_{2} / \mathrm{MeOH}$ 99:1) to give $950 \mathrm{mg}$ $(1.83 \mathrm{mmol}$, yield $55 \%)$ of $\mathbf{3}$ as an orange solid. ${ }^{1} \mathrm{H}$ NMR $\left(\mathrm{CDCl}_{3}\right): \delta=0.87$ $\left(\mathrm{t}, J^{3}=7 \mathrm{~Hz}, 3 \mathrm{H}\right), 1.10-1.24(\mathrm{~m}, 6 \mathrm{H}), 1.33\left(\mathrm{t}, J^{3}=7 \mathrm{~Hz}, 3 \mathrm{H}\right), 2.85-3.60(\mathrm{~m}$, $7 \mathrm{H}), 3.87(\mathrm{~s}, 1 \mathrm{H}), 4.30(\mathrm{~m}, 1 \mathrm{H}), 6.8-8.0 \mathrm{ppm}(\mathrm{m}, 9 \mathrm{H})$; EI-MS: $m / z: 548$ $[M]^{+}$.

Preparation of 2,6-pyridinedicarboxylic acid bis $\{N$-ethyl- $N$ - $\{5-\{4-[N-6$ $(\mathrm{N}, \boldsymbol{N}$-diethylcarbamoyl)pyridin-2-carbonyl- $\boldsymbol{N}$-ethyl] amino\}-3-nitroben-

zyl)nitrophenyl\}amide (4): Pyridine-2,6-dicarbonylchloride (186 mg, $0.91 \mathrm{mmol}$ ) was added in three portions $(93 \mathrm{mg}, 47 \mathrm{mg}, 45 \mathrm{mg}$ ) into a solution of $\mathbf{3}(500 \mathrm{mg}, 0.91 \mathrm{mmol})$ in dichloromethane $(165 \mathrm{~mL})$. The mixture was refluxed for $12 \mathrm{~h}$ under an inert atmosphere after each addition. The resulting dark solution was evaporated and dried under vacuum. The residue was partitioned between dichloromethane $(100 \mathrm{~mL})$ and half-saturated aqueous $\mathrm{NH}_{4} \mathrm{Cl}$ solution $(100 \mathrm{~mL})$. The aqueous phase was extracted with dichloromethane $(3 \times 100 \mathrm{~mL})$, and the combined organic phases were dried $\left(\mathrm{Na}_{2} \mathrm{SO}_{4}\right)$ and evaporated. The crude product was purified by column chromatography (silicagel, $\mathrm{CH}_{2} \mathrm{Cl}_{2} / \mathrm{MeOH}$ 98.5:1.5 $\rightarrow \mathrm{CH}_{2} \mathrm{Cl}_{2} / \mathrm{MeOH}$ 97:3) to give $465 \mathrm{mg}(0.38 \mathrm{mmol}$, yield $84 \%$ ) of 4 as pale yellow solid. M.p. $126-127{ }^{\circ} \mathrm{C} ;{ }^{1} \mathrm{H}$ NMR $\left(\mathrm{CDCl}_{3}\right): \delta=0.8-1.3$ $(\mathrm{m}, 24 \mathrm{H}), 2.90-4.4(\mathrm{~m}, 20 \mathrm{H}), 7.0-8.0 \mathrm{ppm}(\mathrm{m}, 21 \mathrm{H})$; ESI-MS $\left(\mathrm{CH}_{2} \mathrm{Cl}_{2}+\right.$ $\left.0.1 \% \mathrm{CF}_{3} \mathrm{CO}_{2} \mathrm{H}\right): m / z: 1228.3[M+\mathrm{H}]^{+}$.

Preparation of 2,6-bis $\{1-e t h y l-5-\{1-e t h y l-2-[6-(N, N$-diethylcarbamoyl)pyridin-2-yl]benzimidazol-5-methylene\}benzimidazole-2-yl\}pyridine (L7): Activated iron powder $(1.22 \mathrm{~g}, 21.9 \mathrm{mmol})$ and concentrated hydrochloric acid
$(37 \%, 2.28 \mathrm{~mL}, 27.4 \mathrm{mmol})$ were added to a solution of 4 (449 mg, $0.365 \mathrm{mmol})$ in ethanol/water $(112 \mathrm{~mL} / 28 \mathrm{~mL})$. The mixture was refluxed for $15 \mathrm{~h}$ under an inert atmosphere, the excess of iron was filtered off, ethanol was distilled under vacuum, and water $(60 \mathrm{~mL})$ was added. A solution of $\mathrm{Na}_{2} \mathrm{H}_{2}$ EDTA $(6.79 \mathrm{~g}, 18.3 \mathrm{mmol})$ in water $(100 \mathrm{~mL})$ was poured into the resulting mixture, and then dichloromethane $(200 \mathrm{~mL})$ was added. The resulting stirred mixture was neutralized $(\mathrm{pH}=7.0)$ with concentrated aqueous $\mathrm{NH}_{4} \mathrm{OH}$ solution. Concentrated $\mathrm{H}_{2} \mathrm{O}_{2}$ solution $(30 \%, 1.0 \mathrm{~mL})$ was added under vigorous stirring, and the $\mathrm{pH}$ was adjusted to 8.5 with aqueous $\mathrm{NH}_{4} \mathrm{OH}$ solution. The organic layer was separated and the aqueous phase extracted with dichloromethane $(3 \times 200 \mathrm{~mL})$. The combined organic phases were dried $\left(\mathrm{Na}_{2} \mathrm{SO}_{4}\right)$ and evaporated, and the crude product was purified by column chromatography (silicagel, $\mathrm{CH}_{2} \mathrm{Cl}_{2} / \mathrm{MeOH}$ 97.5:2.5 $\rightarrow$ $96: 4)$, and then crystallized from a dichloromethane/hexane mixture to give $347 \mathrm{mg}(3.29 \mathrm{mmol}$, yield $90 \%)$ of $\mathrm{L} 7 \cdot \mathrm{H}_{2} \mathrm{O}$ as a white solid. M.p. $>200{ }^{\circ} \mathrm{C} .{ }^{1} \mathrm{H}$ NMR $\left(\mathrm{CDCl}_{3}\right): \delta=1.04\left(\mathrm{t}, J^{3}=7 \mathrm{~Hz}, 6 \mathrm{H}\right), 1.25\left(\mathrm{t}, J^{3}=7 \mathrm{~Hz}\right.$, $6 \mathrm{H}), 1.31\left(\mathrm{t}, J^{3}=7 \mathrm{~Hz}, 6 \mathrm{H}\right), 1.42\left(\mathrm{t}, J^{3}=7 \mathrm{~Hz}, 6 \mathrm{H}\right), 3.31\left(\mathrm{q}, J^{3}=7 \mathrm{~Hz}, 4 \mathrm{H}\right)$, $3.57\left(\mathrm{q}, J^{3}=7 \mathrm{~Hz}, 4 \mathrm{H}\right), 4.27(\mathrm{~s}, 4 \mathrm{H}), 4.71\left(\mathrm{q}, J^{3}=7 \mathrm{~Hz}, 4 \mathrm{H}\right), 4.72\left(\mathrm{q}, J^{3}=\right.$ $7 \mathrm{~Hz}, 4 \mathrm{H}), 7.22\left(\mathrm{~d}, J^{3}=8 \mathrm{~Hz}, 4 \mathrm{H}\right), 7.33\left(\mathrm{~d}, J^{3}=8 \mathrm{~Hz}, 2 \mathrm{H}\right), 7.34\left(\mathrm{dd}, J^{3}=\right.$ $\left.8 \mathrm{~Hz}, J^{4}=1 \mathrm{~Hz}, 2 \mathrm{H}\right), 7.51\left(\mathrm{~d}, J^{3}=8 \mathrm{~Hz}, 2 \mathrm{H}\right), 7.69$ (brs, 2H), 7.71 (br s, 2H), $7.91\left(\mathrm{t}, J^{3}=8 \mathrm{~Hz}, 2 \mathrm{H}\right), 8.00\left(\mathrm{t}, J^{3}=8 \mathrm{~Hz}, 1 \mathrm{H}\right), 8.30\left(\mathrm{~d}, J^{3}=8 \mathrm{~Hz}, 2 \mathrm{H}\right)$, $8.37 \mathrm{ppm}\left(\mathrm{d}, J^{3}=8 \mathrm{~Hz}, 2 \mathrm{H}\right)$; elemental analysis calcd $(\%)$ for $\mathrm{L} 7 \cdot \mathrm{H}_{2} \mathrm{O}$ $\left(\mathrm{C}_{63} \mathrm{H}_{67} \mathrm{~N}_{13} \mathrm{O}_{3}\right)$ : C 71.77, H 6.41, N 17.27; found C 71.72, H 6.42, N 17.14; ESIMS $\left(\mathrm{CH}_{2} \mathrm{Cl}_{2}+0.1 \% \mathrm{CF}_{3} \mathrm{CO}_{2} \mathrm{H}\right): m / z: 1036.6[M+\mathrm{H}]^{+}$.

Preparation of 2,6-bis\{1-ethyl-5-\{1-ethyl-2-[6-carboxypyridin-2-yl]benzimidazol-5-methylene\}benzimidazole-2-yl\}pyridine (L8): Ligand $\mathrm{L} 7 \cdot \mathrm{H}_{2} \mathrm{O}$ $(50 \mathrm{mg}, 0.048 \mathrm{mmol})$ and potassium hydroxide $(86 \%, 1.58 \mathrm{~g}, 24.2 \mathrm{mmol})$ were refluxed in ethanol/water $(10 \mathrm{~mL} / 2.5 \mathrm{~mL})$ for $15 \mathrm{~h}$. The ethanol was distilled under vacuum, water $(25 \mathrm{~mL})$ was added, and the aqueous phase extracted with dichloromethane $(3 \times 25 \mathrm{~mL})$. The aqueous phase was neutralized $(\mathrm{pH}=3.0)$ with concentrated hydrochloric acid $(37 \%)$ and the resulting precipitate was filtered, washed with water $(5 \mathrm{~mL})$, and dried to give $32 \mathrm{mg}(0.03 \mathrm{mmol}$, yield $62 \%)$ of $\mathrm{K}(\mathrm{L} 8-\mathrm{H}) \cdot 5.6 \mathrm{H}_{2} \mathrm{O}$ as a white powder. M.p. $>200{ }^{\circ} \mathrm{C} ;{ }^{1} \mathrm{H}$ NMR ([D $]$ DMSO): $\delta=1.27\left(\mathrm{t}, J^{3}=7 \mathrm{~Hz}, 6 \mathrm{H}\right), 1.40(\mathrm{t}$, $\left.J^{3}=7 \mathrm{~Hz}, 6 \mathrm{H}\right), 4.22(\mathrm{~s}, 4 \mathrm{H}), 4.78\left(\mathrm{q}, J^{3}=7 \mathrm{~Hz}, 4 \mathrm{H}\right), 4.88\left(\mathrm{q}, J^{3}=7 \mathrm{~Hz}, 4 \mathrm{H}\right)$, $7.28\left(\mathrm{~d}, J^{3}=8 \mathrm{~Hz}, 4 \mathrm{H}\right), 7.60\left(\mathrm{~d}, J^{3}=8 \mathrm{~Hz}, 2 \mathrm{H}\right), 7.63\left(\mathrm{~d}, J^{3}=8 \mathrm{~Hz}, 2 \mathrm{H}\right), 7.66$ (brs, $2 \mathrm{H}), 7.68($ brs, $2 \mathrm{H}), 8.10-8.20\left(\mathrm{~m}, J^{3}=8 \mathrm{~Hz}, 3 \mathrm{H} ; A B_{2}\right), 8.20\left(\mathrm{t}, J^{3}=\right.$ $8 \mathrm{~Hz}, 2 \mathrm{H}), 8.31\left(\mathrm{~d}, J^{3}=8 \mathrm{~Hz}, 2 \mathrm{H}\right), 8.49 \mathrm{ppm}\left(\mathrm{d}, J^{3}=8 \mathrm{~Hz}, 2 \mathrm{H}\right)$; elemental analysis calcd (\%) for $\mathrm{K}(\mathrm{L} 8-\mathrm{H}) \cdot 5.6 \mathrm{H}_{2} \mathrm{O}\left(\mathrm{C}_{55} \mathrm{H}_{46} \mathrm{~N}_{11} \mathrm{O}_{4} \cdot 5.6 \mathrm{H}_{2} \mathrm{O}\right)$ : C 62.05, $\mathrm{H}$ 5.41, N 14.47; found C 62.06, H 5.09, N 14.27; ESI-MS (DMSO + $0.1 \%$ $\mathrm{CF}_{3} \mathrm{CO}_{2} \mathrm{H}$ ): $m / z: 926.5[\mathrm{~L} 8+\mathrm{H}]^{+}, 463.8[\mathrm{~L} 8+2 \mathrm{H}]^{2+}$; ESI-MS (DMSO, positive mode): $m / z: 926.3[\mathrm{~L} 8+\mathrm{H}]^{+}, 964.1[\mathrm{~L} 8+\mathrm{K}]^{+}$; (DMSO, negative mode): $m / z: 924.5[\mathrm{~L} 8-\mathrm{H}]^{-}$

Preparation of the complexes $\left[\mathrm{Ln}_{3}(\mathrm{L7})_{3}\right]\left(\mathrm{CF}_{3} \mathrm{SO}_{3}\right)_{9} \cdot x \mathrm{H}_{2} \mathrm{O}[\mathrm{Ln}=\mathrm{La}, x=4$ (5); $\mathbf{L n}=\mathbf{E u}, x=4$ (6); Ln $=\mathbf{G d}, x=2$ (7); $\mathbf{L n}=\mathbf{T b}, x=12$ (8); $\mathbf{L n}=\mathbf{L u}$, $\boldsymbol{x}=6(9)]$ and $\left[\mathrm{Eu}_{3}\left(\mathrm{L7}_{3}\right)_{3}\right]\left(\mathrm{CF}_{3} \mathrm{SO}_{3}\right)_{9} \cdot\left(\mathrm{CH}_{3} \mathrm{CN}\right)_{9} \cdot\left(\mathrm{H}_{2} \mathrm{O}\right)_{2}(10)$ : A solution of $\mathrm{Ln}\left(\mathrm{CF}_{3} \mathrm{SO}_{3}\right)_{3} \cdot x \mathrm{H}_{2} \mathrm{O}(\mathrm{Ln}=\mathrm{La}, \mathrm{Eu}, \mathrm{Gd}, \mathrm{Tb}, \mathrm{Lu} ; x=1-4 ; 0.048 \mathrm{mmol})$ in acetonitrile $(3 \mathrm{~mL})$ was added to a solution of $\mathrm{L} 7 \cdot \mathrm{H}_{2} \mathrm{O}(50 \mathrm{mg}$, $0.048 \mathrm{mmol})$ in acetonitrile/dichloromethane $(1.5 \mathrm{~mL} / 1.5 \mathrm{~mL})$. After stirring for $1 \mathrm{~h}$ at room temperature, the solution was evaporated, the solid residue dissolved in $\mathrm{MeCN}(1 \mathrm{~mL})$, and $\mathrm{Et}_{2} \mathrm{O}$ was diffused into the solution for 1 day. The resulting white microcrystalline powders were collected by filtration and dried to give $77-89 \%$ of $\left[\mathrm{Ln}_{3}(\mathrm{~L} 7)_{3}\right]\left(\mathrm{CF}_{3} \mathrm{SO}_{3}\right)_{9} \cdot x \mathrm{H}_{2} \mathrm{O}(\mathrm{Ln}=$ $\mathrm{La}, x=4(5) ; \mathrm{Ln}=\mathrm{Eu}, x=4(\mathbf{6}) ; \mathrm{Ln}=\mathrm{Gd}, x=2(\mathbf{7}) ; \mathrm{Ln}=\mathrm{Tb}, x=12(\mathbf{8})$; $\mathrm{Ln}=\mathrm{Lu}, \quad x=6 \quad(9))$. The same procedure was followed for $\left[\mathrm{Eu}_{3^{-}}\right.$ $\left.(\mathrm{L} 7)_{3}\right]\left(\mathrm{CF}_{3} \mathrm{SO}_{3}\right)_{9}\left(\mathrm{CH}_{3} \mathrm{CN}\right)_{9}\left(\mathrm{H}_{2} \mathrm{O}\right)_{2}(\mathbf{1 0})$ except that the crystals were transferred directly from the mother liquor onto the diffractometer. The complexes gave satisfactory elemental analyses (Table S2, Supporting information), and IR, NMR, and ESI-MS spectra.

Preparation of the complexes $\left[\mathrm{Ln}_{3}\left(\mathrm{L7}_{3}\right)_{3}\right]\left(\mathrm{CF}_{3} \mathrm{SO}_{3}\right)_{9}(\mathrm{Ln}=\mathrm{Ce}, \mathrm{Pr}, \mathrm{Nd}, \mathrm{Sm}$, Dy, Ho, Er, Tm, Yb): $\left[\mathrm{Ln}_{3}(\mathrm{~L} 7)_{3}\right]\left(\mathrm{CF}_{3} \mathrm{SO}_{3}\right)_{9}$ were prepared in situ for ${ }^{1} \mathrm{H}$ NMR studies. A solution of $\mathrm{Ln}\left(\mathrm{CF}_{3} \mathrm{SO}_{3}\right)_{3} \cdot x \mathrm{H}_{2} \mathrm{O}\left(9.48 \times 10^{-6} \mathrm{~mol}\right)$ in acetonitrile $(1 \mathrm{~mL})$ was added to a solution of $\mathrm{L} 7 \cdot \mathrm{H}_{2} \mathrm{O}(10 \mathrm{mg}, 9.48 \times$ $\left.10^{-6} \mathrm{~mol}\right)$ in $1: 2 \mathrm{CH}_{2} \mathrm{Cl}_{2}: \mathrm{MeCN}(1.5 \mathrm{~mL})$. After stirring $3 \mathrm{~h}$ at room temperature, the solution was evaporated and dried under vacuum, and the solid residue dissolved in $\mathrm{CD}_{3} \mathrm{CN}(700 \mu \mathrm{L})$.

Crystal structure determination of $\left[\mathrm{Eu}_{3}\left(\mathrm{L7}_{3}\right)_{3}\right]\left(\mathrm{CF}_{3} \mathrm{SO}_{3}\right)_{\mathbf{9}}\left(\mathrm{CH}_{3} \mathrm{CN}\right)_{\mathbf{9}}\left(\mathrm{H}_{2} \mathrm{O}\right)_{2}$ (10): $\quad \mathrm{Eu}_{3} \mathrm{C}_{216} \mathrm{H}_{226} \mathrm{~N}_{48} \mathrm{O}_{35} \mathrm{~F}_{27} \mathrm{~S}_{9} ; \quad M_{\mathrm{r}}=5312.2 ; \quad \mu=0.95 \mathrm{~mm}^{-1}, \quad \rho_{\text {calcd }}=$ $1.470 \mathrm{~g} \mathrm{~cm}^{-3}$, triclinic, $P \overline{1}, \quad Z=2, \quad a=14.9286(7), \quad b=21.7201(11), \quad c=$ 39.2254(17) $\AA, \quad \alpha=96.885(5), \quad \beta=99.428(5), \quad \gamma=104.033(6)^{\circ}, \quad V=$ $12002(1) \AA^{3}$; pale yellow prism $0.12 \times 0.32 \times 0.35 \mathrm{~mm}$ mounted on a quartz 
fiber with protection oil. Cell dimensions and intensities were measured at $200 \mathrm{~K}$ on a Stoe IPDS diffractometer with graphite-monochromated $\mathrm{Mo}_{\mathrm{K} \alpha}$ radiation $(\lambda=0.7107 \AA) ; 131723$ measured reflections, $2 \theta_{\max }=51.9^{\circ}, 42677$ unique reflections of wich 22616 were observed $\left[\left|F_{\mathrm{o}}\right|>4 \sigma\left(F_{\mathrm{o}}\right)\right] ; R_{\text {int }}$ for 89046 equivalent reflections 0.071 . Data were corrected for Lorentz and polarization effects and for absorption $(\mathrm{min} / \mathrm{max}$ transmission $=0.7552 /$ 0.8963). The structure was solved by direct methods (SIR97) $;{ }^{[61]}$ all other calculation were performed with XTAL system ${ }^{[62]}$ and ORTEP ${ }^{[63]}$ programs. Full-matrix least-squares refinement based on $F$ using weight of 1/ $\left(\sigma^{2}\left(F_{\mathrm{o}}\right)+0.0001\left(F_{\mathrm{o}}^{2}\right)\right)$ gave final values $R=0.055, \omega R=0.055$, and $S=$ 1.814(9) for 3024 variables and 24081 contributing reflections. The final difference electron density map showed a maximum of +1.29 and a minimum of $-1.62 \mathrm{e}^{-3}$. The hydrogen atoms were placed in calculated positions and contributed to $F_{\mathrm{c}}$ calculations. The methyl group C53a was disordered and refined with two distinct atomic sites and population parameters of $0.7 / 0.3$. The anions were refined with isotropic displacement parameters and restraints on bond distances and bond angles.

CCDC-180632 (10) contains the supplementary crystallographic data for this paper. These data can be obtained free of charge via www.ccdc.cam. ac.uk/conts/retrieving.html (or from the Cambridge Crystallographic Data Centre, 12 Union Road, Cambridge CB21EZ (UK); fax: (+44)1223-336033; or deposit@ccdc.cam.uk).

Spectroscopic and analytical measurements: Reflectance spectra were recorded as finely ground powders dispersed in $\mathrm{MgO}(5 \%)$ with $\mathrm{MgO}$ as reference on a Perkin-Elmer Lambda 900 spectrometer equipped with a PELA-1020 integrating sphere from Labsphere. Electronic spectra in the $\mathrm{UV}$-visible region were recorded at $25^{\circ} \mathrm{C}$ from solutions in $\mathrm{MeCN}$ with a Perkin - Elmer Lambda 900 spectrometer by using quartz cells of 0.1 and $1 \mathrm{~mm}$ path length. Spectrophotometric titrations were performed in batch at $25^{\circ} \mathrm{C}$ with a Perkin -Elmer Lambda 900 spectrometer by using quartz cells of $1 \mathrm{~mm}$ path length. Acetonitrile solutions containing a total ligand concentration of $2 \times 10^{-4} \mathrm{M}$ and variable concentrations of $\mathrm{Ln}\left(\mathrm{CF}_{3} \mathrm{SO}_{3}\right)_{3}$. $x \mathrm{H}_{2} \mathrm{O}\left(\mathrm{Ln}^{\mathrm{III}}: \mathrm{L} 7=0.1-5.0,40-50\right.$ samples $)$ were left to equilibrate $48 \mathrm{~h}$ at $298 \mathrm{~K}$. The absorption spectrum of each sample was transferred to the computer. Mathematical treatment of the spectrophotometric titrations was performed with factor analysis ${ }^{[23]}$ and with the SPECFIT program..$^{[24]}$ IR spectra were obtained from $\mathrm{KBr}$ pellets with a Perkin-Elmer 883 spectrometer. ${ }^{1} \mathrm{H}$ NMR spectra were recorded at $25^{\circ} \mathrm{C}$ on a Broadband Varian Gemini 300 spectrometer. Chemical shifts are given in ppm with TMS as the reference. EI-MS $(70 \mathrm{eV})$ were recorded with VG-7000E and Finnigan-4000 instruments. Pneumatically-assisted electrospray (ESI-MS) mass spectra were recorded from $10^{-4} \mathrm{M}$ acetonitrile solutions on API III and API 3000 tandem mass spectrometers (AB/MDS Sciex) by infusion at 4-10 $\mu \mathrm{L} \mathrm{min}^{-1}$. The spectra were recorded under low up-front declustering or collision induced dissociation (CID) conditions, typically $\Delta V=0-30 \mathrm{~V}$ between the orifice and the first quadrupole of the spectrometer. The experimental procedures for high-resolution, laser-excited luminescence measurements have been published previously. ${ }^{[64]}$ Solid-state samples were finely powdered and low temperatures $(295-10 \mathrm{~K})$ were achieved by means of a Cryodyne Model 22 closed-cycle refrigerator from CTI Cryogenics. Luminescence spectra were corrected for the instrumental function, but not excitation spectra. Lifetimes are averages of at least 3 5 independent determinations and were measured using excitation provided by a Quantum Brillant Nd:YAG laser equipped with frequency doubler, tripler, and quadrupler as well as with an OPOTEK MagicPrism ${ }^{\mathrm{TM}}$ OPO crystal. Ligand excitation and emission spectra, as well as quantum yields were recorded on a Perkin-Elmer LS-50B spectrometer equipped for low-temperature measurements. The quantum yields $\Phi$ were calculated by using the Equation (14), in which $\mathrm{x}$ refers to the sample and $\mathrm{r}$ to the reference; $A$ is the absorbance, $\tilde{v}$ the excitation wavenumber used, $I$ the intensity of the excitation light at this energy, $n$ the refractive index and $D$ the integrated emitted intensity. $\left[\mathrm{Eu}(\text { terpy })_{3}\right]\left(\mathrm{ClO}_{4}\right)_{3}(\Phi=1.3 \%$, acetonitrile, $\left.10^{-3} \mathrm{M}\right)$ and $\left[\mathrm{Tb}(\text { terpy })_{3}\right]\left(\mathrm{ClO}_{4}\right)_{3}\left(\Phi=4.7 \%\right.$, acetonitrile, $\left.10^{-3} \mathrm{M}\right)$ were used as references for the determination of quantum yields of respectively Eu- and Tb-containing samples. ${ }^{[33,52]}$ Elemental analyses were performed by Dr. H. Eder from the microchemical Laboratory of the University of Geneva.

$\frac{\Phi_{\mathrm{x}}}{\Phi_{\mathrm{r}}}=\frac{A_{\mathrm{r}}(\widetilde{\mathcal{v}}) I_{\mathrm{r}}(\widetilde{\mathcal{v}}) n_{\mathrm{x}}^{2} D_{\mathrm{x}}}{A_{\mathrm{x}}(\widetilde{\mathcal{v}}) I_{\mathrm{x}}(\widetilde{v}) n_{\mathrm{r}}^{2} D_{\mathrm{r}}}$

\section{Acknowledgement}

We are grateful to Ms. Hélène Lartigue, Mr. Laurent Gaudard and Mr. Frédéric Gumy for technical assistance. This work was supported through grants from the Swiss National Science Foundation.

[1] a) L. Fabbrizzi, M. Licchelli, P. Pallavicini, Acc. Chem. Res. 1999, 32 , 846; b) C. Piguet, J. Inclusion Phenom. Macrocyclic Chem. 1999, 34, 361; c) V. Balzani, A. Credi, F. M. Raymo, J. F. Stoddart, Angew. Chem. 2000, 112, 3484; Angew. Chem. Int. Ed. 2000, 39, 3348.

[2] N. Kaltsoyannis, P. Scott, The f-Elements, Oxford University Press, Oxford, 1999

[3] a) W. T. Carnall, in Handbook on the Physics and Chemistry of Rare Earths (Eds.: K. A. Gschneidner, Jr., L. Eyring), North-Holland, Amsterdam, 1979, pp. 171-208; b) C. Görller-Walrand, K. Binnemans, in Handbook on the Physics and Chemistry of Rare Earths, Vol. 23 (Eds.: K. A. Gschneidner, Jr., L. Eyring), North-Holland, Amsterdam, 1996, pp. 121 -283; c) P. Porcher, in Rare Earths (Eds.: R. Saez Puche, P. Caro), Editorial Complutense, Madrid, 1998, pp. $43-$ 66.

[4] J.-C. G. Bünzli, C. Piguet, Chem. Rev. 2002, 102, 1897.

[5] a) S. Kobayashi, Top. Organomet. Chem. 1999, 2, 63; b) H. Sasai, T Suzuki, N. Itoh, K. Tanaka, T. Date, K. Okamura, M. Shibasaki, J. Am. Chem. Soc. 1993, 115, 10372; c) E. Emori, T. Arai, H. Sasai, M. Shibasaki, J. Am. Chem. Soc. 1998, 120, 4043.

[6] a) M. P. Lowe, D. Parker, O. Reany, S. Aime, M. Botta, G. Castellano, E. Gianolio, R. Pagliarin, J. Am. Chem. Soc. 2001, 123, 7601; b) Y. Bretonnière, M. Mazzanti, J. Pécaut, F. A. Dunand, A. E. Merbach, Inorg. Chem. 2001, 40, 6737; c) C. J. Sunderland, M. Botta, S. Aime, K. N. Raymond, Inorg. Chem. 2001, 40, 6746.

[7] a) G. Bobba, R. S. Dickins, S. D. Kean, C. E. Mathieu, D. Parker, R. D. Peacock, G. Siligardi, M. J. Smith, J. A. G. Williams, C. F. G. C Geraldes, C. F. G. C. J. Chem. Soc. Perkin 2 2001, 1729; b) G. Bobba, S. D. Kean, D. Parker, A. Beeby, G. Baker, J. Chem. Soc. Perkin 2 2001, 1738; c) G. Bobba, J. C. Frias, D. Parker, Chem. Commun. 2002, 890

[8] K. Binnemans, Y. G. Galyametdinov, R. Van Deun, D. W. Bruce, S. R. Collinson, A. P. Polishchuk, I. Bikchantaev, W. Haase, A. V. Prosvirin, L. Tinchurina, U. Litvinov, A. Gubajdullin, A. Rakhmatullin, K. Uytterhoeven, L. Van Meervelt, J. Am. Chem. Soc. 2000, 122, 4335.

[9] a) E. Toth, L. Helm, A. E. Merbach, R. Hedinger, K. Hegetschweiler, A. Janossy, Inorg. Chem. 1998, 37, 4104; b) V. Comblin, D. Gilsoul, M. Hermann, V. Humblet, V. Jacques, M. Mesbahi, C. Sauvage, J. F. Desreux, Coord. Chem. Rev. 1999, 185/186, 451; c) N. Fatin-Rouge, E. Toth, D. Perret, R. H. Backer, A. E. Merbach, J.-C. G. Bünzli, J. Am. Chem. Soc. 2000, 122, 10810; d) G. M. Nicolle, E. Toth, H. SchmittWillich, B. Radüchel, A. E. Merbach, Chem. Eur. J. 2002, 8, 1040.

[10] a) K. Hsu, C. M. Miller, J. T. Kringlebotn, E. M. Taylor, J. Townsend, D. N. Payne, Opt. Lett. 1994, 19, 886; b) R. C. Howell, K. V. N. Spence, I. A. Kahwa, D. J. Williams, J. Chem. Soc. Dalton Trans. 1998, 2727; c) Y. Shen, T. Riedener, K. L. Bray, Phys. Rev. B. 2000, 61, 11460.

[11] R. C. Howell, K. V. N. Spence, I. A. Kahwa, A. J. P. White, D. J. Williams, J. Chem. Soc. Dalton Trans. 1996, 961.

[12] C. Piguet, C. Edder, S. Rigault, G. Bernardinelli, J.-C. G. Bünzli, G. Hopfgartner, J. Chem. Soc. Dalton Trans. 2000, 3999.

[13] C. Piguet, J.-C. G. Bünzli, G. Bernardinelli, G. Hopfgartner, A. F. Williams, J. Am. Chem. Soc. 1993, 115, 8197.

[14] N. Martin, J.-C. G. Bünzli, V. McKee, C. Piguet, G. Hopfgartner, Inorg. Chem. 1998, 37, 577.

[15] M. Elhabiri, R. Scopelliti, J.-C. G. Bünzli, C. Piguet, J. Am. Chem. Soc. 1999, 121, 10747.

[16] J. L. Lessmann, W. DeW. Horrocks, Jr., Inorg. Chem. 2000, 39, 3114.

[17] S. Rigault, C. Piguet, J.-C. G. Bünzli, J. Chem. Soc. Dalton Trans. 2000, 2045.

[18] M. Cantuel, G. Bernardinelli, D. Imbert, J.-C. G. Bünzli, G. Hopfgartner, C. Piguet, J. Chem. Soc. Dalton Trans. 2002, 1929.

[19] N. André, R. Scopelliti, G. Hopfgartner, C. Piguet, J.-C. G. Bünzli, Chem. Commun. 2002, 214.

[20] C. Piguet, J.-C. G. Bünzli, G. Bernardinelli, G. Hopfgartner, A. F. Williams, J. Alloys Compd. 1995, 225, 324. 
[21] B. Bocquet, G. Bernardinelli, N. Ouali, S. Floquet, F. Renaud, G. Hopfgartner, C. Piguet, Chem. Commun. 2002, 930.

[22] C. Piguet, J.-C. G. Bünzli, G. Bernardinelli, G. Hopfgartner, S. Petoud, O. Schaad, J. Am. Chem. Soc. 1996, 118, 6681

[23] E. R. Malinowski, D. G. Howery, Factor Analysis in Chemistry, Wiley, New York, Chichester, 1980.

[24] a) H. Gampp, M. Maeder, C. J. Meyer, A. D. Zuberbühler, Talanta 1986, 33, 943; b) H. Gampp, M. Maeder, C. J. Meyer, A. D. Zuberbühler, Talanta, 1985, 23, 1133.

[25] S. Petoud, J.-C. G. Bünzli, F. Renaud, C. Piguet, K. J. Schenk, G. Hopfgartner, Inorg. Chem. 1997, 36, 5750.

[26] a) B. Perlmutter-Hayman, Acc. Chem. Res. 1986, 19, 90; b) G. Scatchard, Ann N.Y. Acad. Sci. 1949, 51, 660.

[27] T. M. Garrett, U. Koert, J.-M. Lehn, J. Phys. Org. Chem. 1992, 5, 529.

[28] A. Pfeil, J.-M. Lehn, J. Chem. Soc. Chem. Commun. 1992, 838.

[29] J. Hamacek, S. Blanc, M. Elhabiri, E. Leize, A. van Dorsselaer, C. Piguet, A.-M. Albrecht-Gary, J. Am. Chem. Soc. 2003, 125, 1541.

[30] J.-L. Pascal, M. E. M. Hamidi, Polyhedron 1994, 13, 1787.

[31] a) J. H. Brewster, Top. Curr. Chem. 1974, 47, 29; b) F. Renaud, C. Piguet, G. Bernardinelli, J.-C. G. Bünzli, G. Hopfgartner, J. Am. Chem. Soc. 1999, 121, 9326.

[32] C. Piguet, J.-C. G. Bünzli, J.-C. G. Bernardinelli, A. F. Williams, Inorg. Chem. 1993, 32, 4139.

[33] F. Renaud, C. Piguet, G. Bernardinelli, J.-C. G. Bünzli, G. Hopfgartner, Chem. Eur. J. 1997, 3, 1646.

[34] C. Piguet, G. Bernardinelli, G. Hopfgartner, Chem. Rev. 1997, 97, 2005.

[35] a) J. A. Peters, J. Huskens, D. J. Raber, Prog. Nucl. Magn. Reson. Spectrosc. 1996, 28, 283; b) J. H. Forsberg in Handbook on the Physics and Chemistry of Rare Earths, Vol. 23 (Eds.: K. A. Gschneidner, Jr., L. Eyring), North-Holland, Amsterdam, 1996, pp. 1-68.

[36] S. Rigault, C. Piguet, G. Bernardinelli, G. Hopfgartner, J. Chem. Soc. Dalton Trans. 2000, 4587.

[37] R. M. Golding, M. P. Halton, Aust. J. Chem. 1972, 25, 2577.

[38] a) B. J. Bleaney, Magn. Reson. 1972, 8, 91; b) B. Bleaney, C. M. Dobson, B. A. Levine, R. B. Martin, R. J. P. Williams, A. V. Xavier, J. Chem. Soc. Chem. Commun. 1972, 791; c) for a recent re-examination see V. S. Mironov, Y. G. Galyametdinov, A. Ceulemans, C. GörllerWalrand, K. Binnemans, J. Chem. Phys. 2002, 116, 4673.

[39] a) C. N. Reilley, B. W. Good, J. F. Desreux, Anal. Chem. 1975, 47, 2110 ; b) A. D. Sherry, C. F. G. C. Geraldes in Lanthanide Probes in Life, Chemical and Earth Sciences, (Eds.: J.-C. G. Bünzli, G. R. Choppin), Elsevier, Amsterdam, 1989, Chapter 4.

[40] J. P. Costes, F. Dahan, A. Dupuis, S. Lagrave, J. P. Laurent, Inorg. Chem. 1998, 37, 153.

[41] S. Rigault, C. Piguet, J. Am. Chem. Soc. 2000, 122, 9304.

[42] C. Platas, F. Avecilla, A. de Blas, C. F. G. C. Geraldes, T. RodriguezBlas, H. Adams, J. Mahia, Inorg. Chem. 1999, 38, 3190.

[43] N. Ouali, J.-P. Rivera, P.-Y. Morgantini, J. Weber, C. Piguet, J. Chem. Soc. Dalton Trans. 2003, in press.
[44] M. R. Wilcott, R. E. Lenkinski, R. E. Davis, J. Am. Chem. Soc. 1972, 94, 1742.

[45] $B_{0}^{2}$ is usually expressed in $\mathrm{cm}^{-1},{ }^{[3]}$ but only relative values (formally in ppm $\AA^{3}$ ) are obtained from paramagnetic NMR data because the Bleaney's factors are arbitrary scaled to $C_{\mathrm{Dy}}=-100$ and are given without units. ${ }^{[38]}$

[46] K. Binnemans, C. Görller-Walrand, Chem. Phys. Lett. 1995, 245, 75.

[47] O. Kahn, Molecular Magnetism, VCH, Weinheim, 1993, p. 46.

[48] A. A. Pinkerton, M. Rossier, S. Spiliadis, J. Magn. Reson. 1985, 64, 420.

[49] W. T. Carnall, P. R. Fields, K. Rajnak, J. Chem. Phys. 1968, 49, 4443

[50] a) S. Tobita, M. Arakawa, I. Tanaka, J. Phys. Chem. 1984, 88, 2697; b) S. Tobita, M. Arakawa, I. Tanaka, J. Phys. Chem. 1985, 89, 5649.

[51] J.-C. G. Bünzli in Lanthanide Probes in Life, Chemical and Earth Sciences; (Eds.: J.-C. G. Bünzli, G. R. Choppin) Elsevier: Amsterdam, 1989, Chapter 7.

[52] S. Petoud, J.-C. G. Bünzli, C. Piguet, Q. Xiang, R. Thummel, J. Luminesc. 1999, 82, 69.

[53] S. T. Frey, W. D. Horrocks, Jr., Inorg. Chim. Acta 1995, 228, 383.

[54] J.-M. Lehn, Supramolecular Chemistry, Concepts and Perspectives, VCH, Weinheim, 1995.

[55] M. Albrecht, Chem. Rev. 2001, 101, 3457.

[56] a) J. S. Lindsey, New J. Chem. 1991, 15, 153; b) D. Philp, J. F. Stoddart, Angew. Chem. 1996, 108, 1242; Angew. Chem. Int. Ed. Engl. 1996, 35, 1154 ; c) M. Mammen, S.-K. Choi, G. M. Whitesides, Angew. Chem. 1998, 110, 2908; Angew. Chem. Int. Ed. 1998, 37, 2754.

[57] V. W. W. Yam, K. K. W. Lo, Coord. Chem. Rev. 1999, 184, 157.

[58] a) M. A. Contreras, J. Ubach, O. Millet, J. Rizo, M. Pons, J. Am. Chem. Soc. 1999, 121, 8947; b) I. Bertini, C. Felli, C. Luchinat, J. Biomol. NMR 2000, 18, 347; c) I. Bertini, M. B. L. Janik, Y.-M. Lee, C. Luchinat, A. Rosato, J. Am. Chem. Soc. 2001, 123, 4181; d) P. Bernardo, R. Barbieri, E. Padros, C. Luchinat, M. Pons, J. Am. Chem. Soc. 2002, 124, 374.

[59] a) T. A. Hopkins, D. H. Metcalf, F. S. Richardson, Inorg. Chem. 1998, 37, 1401; b) J. Ren, A. D. Sherry, J. Magn. Reson. 1996, B111, 178.

[60] G. Schwarzenbach, Complexometric Titrations, Chapman and Hall, London, 1957, p. $8 \mathrm{ff}$.

[61] A. Altomare, M. C. Burla, M. Camalli, G. Cascarano, C. Giacovazzo, A. Guagliardi, A. G. G. Moliterni, G. Polidori, R. Spagna, J. Appl. Crystallogr. 1999, 32, 115.

[62] XTAL 3.2: User's Manual (Eds.: S. R. Hall, H. D. Flack, J. M. Stewart), Universities of Western Australia and Maryland, 1989.

[63] C. K. Johnson, ORTEP II; Report ORNL-5138, Oak Ridge National Laboratory, Oak Ridge, Tennessee, 1976.

[64] R. Rodriguez-Cortinas, F. Avecilla, C. Platas-Iglesias, D. Imbert, J.C. G. Bünzli, A. de Blas, T. Rodriguez-Blas, Inorg. Chem. 2002, 41, 5336.

Received: October 16, 2002 [F4503] 